\title{
LA ESTRUCTURA SOCIAL Y EL APOYO PARTIDISTA EN ESPANA*
}

\author{
Arnold S. Feldman \\ Northwestern University, Chicago \\ Jorge R. Menés y Natalia García-Pardo \\ Centro de Investigaciones Sociológicas
}

\begin{abstract}
RESUMEN. En este artículo se investiga la relación entre las posiciones que ocupan los individuos en la División Social del Trabajo (categorías socioestructurales) y su comporta+ miento electoral. Mediante el desarrollo de un modelo teórico de relaciones entre esas dos dimensiones, se analiza la estabilidad del sistema de partidos en España, como quedó definido tras las elecciones generales de 1986. Los datos provienen de una macro-encuesta realizada por el CIS en marzo de 1988, que permite un tratamiento muy detallado y novedoso de las variables del modelo (Situación Laboral, Ocupación y Rama de Actividad, por un lado, y Recuerdo de Voto, por otro). En el análisis se han empleado los residuos ajustados del Gi-cuadrado, producto del cruce entre las variables de estructura social y el Recuerdo de Voto, para determinar la probabilidad de apoyo a los diferentes partidos en cada una de las categorías estructurales. Los resultados destacan por su riqueza descriptiva y confirman la estabilidad del sistema actual de partidos en España. Resulta improbable un cambio drástico en los apoyos recibidos por cada partido de ámbito nacional, lo que, básicamente, dejaría en manos del partido gobernante el mantener o perder su actual hegemonia politica.
\end{abstract}

\section{INTRODUCCION}

Este estudio investiga las relaciones entre la División del Trabajo y la formación de los partidos políticos en la sociedad española. Intentamos determinar en qué posiciones socioestructurales, derivadas de la división del trabajo, se encuentran arraigados un conjunto de partidos políticos.

* Ponencia presentada en el III Congreso de Sociología, Donostia-San Sebastián, 29 de septiembre de 1989. 
Dicho de otro modo, estamos interesados en la estructura de apoyos que diferencia a los partidos políticos en competencia, y en la influencia que ejercen las distintas posiciones de la división del trabajo, donde encuentran sus electorados los diferentes partidos, sobre dicha estructura de apoyos.

Concebimos la estructura de apoyo a los partidos como una tendencia construida sociohistóricamente en el seno de la sociedad, que consiste tanto en una estructura como en un proceso. Nuestro objetivo es revelar tanto de esa estructura y del proceso como lo permita un estudio transversal de encuesta. Estamos especialmente interesados en las implicaciones para el cambio politico y la estabilidad del sistema de partidos.

El sistema político posterior a Franco que surgió en España en la última década ofrece un gran interés en la actualidad. Se considera a España como uno de los ejemplos más recientes y extraños de éxito en la transformación pacífica y bastante rápida de una autocracia en una democracia multipartidista. En efecto, este proceso a menudo se describe como «El milagro español». Y los logros del sistema político español en este período más bien corto de tiempo son bastante impresionantes. No obstante, la estabilidad del sistema debe considerarse problemática por varias razones.

Primero, porque, como ya hemos observado, el sistema sólo existe desde hace aproximadamente una década. Segundo, porque durante este tiempo se ha modificado la naturaleza de la división del trabajo y el número y tipo de partidos, y tanto uno como otro aspecto continúan cambiando. Tercero, porque las demandas regionales de autonomía nacional y los conflictos políticos asociados a éstas subsisten como una amenaza.

Sin embargo, aunque el sistema vigente de partidos nacionales se formó, en algunos casos, mediante coaliciones de fragmentos muy dispares y a menudo competidores entre sí (como la UCD), parece estar evolucionando hacia la consolidación de varios partidos importantes, con electorados bastante bien definidos.

Por supuesto que el «modelo» español de transición de una autocracia a una democracia no es igualmente aplicable a otras sociedades que están ahora intentando abordar el mismo proceso. Los límites vienen impuestos tanto por factores exógenos (como el apoyo militar y económico estadounidense y la creciente importancia de la Comunidad Europea) como endógenos; pero no es éste el lugar para detenernos en el análisis de dichos aspectos.

En cualquier caso, España debería considerarse como un posible modelo de transición exitosa de una autocracia a una democracia multipartidista estable. $Y$ aunque es probable que se produzcan cambios ulteriores en el sistema de partidos, es muy improbable que varíe el carácter fundamentalmente democrático del sistema po'ítico. En la actualidad, existe suficiente «juego» en dicho sistema como para esperar una continuidad del proceso. $Y$, por lo tanto, cualquier información estructural sobre el sistema político español tiene un interés considerable. 


\section{TEORIA Y CONCEPTOS}

\section{El concepto de legitimidad begemónica}

Un eje sobre el que han girado los análisis previos de las relaciones entre la división del trabajo y la existencia de una democracia de partidos es la medida en que los partidos políticos están limitados a ocupar una posición determinada en la División Industrial del Trabajo (DIT). Gran parte de este tipo de estudios tiene un corte marxista. La mejor obra conocida de Marx en este sentido está contenida en sus escritos sobre Francia y, especialmente, en el 18 Brumario.

Quizá la conceptualización más sofisticada posterior a este autor sea la de Gramsci ${ }^{1}$, quien revisó algunas ideas de Marx. En lugar de asumir que la DIT y las organizaciones políticas asociadas a ésta se disolverían, argumentó lo siguiente:

1) Cualquier partido iba a tener que enfrentarse a formaciones sociales que contienen diferentes categorías de la DIT, esto es, clases «objetivas» y fracciones de clases.

2) La División del Trabajo no sólo iba a mantenerse, sino que, además, cobraría bastante dinamismo. Las categorías sufrirían modificaciones tanto en su contenido como en su tamaño relativo. A Gramsci, que escribía en los años veinte y treinta, le interesaba analizar el desarrollo del Fordismo y sus efectos sobre la estructura familiar y los roles de los distintos sexós? Sin embargo, esas tendencias son también identificables en otros ejemplos más contemporáneos, como la incorporación de expertos en marketing de orientación burocrática y tecnológica en un estrato específico de gestores; o la reciente contracción del trabajo cualificado, debida a la adopción del control numérico automatizado, y la subsiguiente expansión del estrato semicualificado de los trabajadores manuales; o la reducción de este último estrato como consecuencia de la automatización basada en robots.

3) Para adquirir un papel importante, un partido tendría que apelar no sólo a su categoría central de la DIT, sino también a otras categorías que seguramente tendrán intereses concretos y dispares. Gramsci argumentó que estos intereses reflejarían diferentes posiciones en la DIT. El proceso de atracción de dichas categorías no centrales se plasmaría en el intento de un partido de hacerse hegemónico, persuadiéndolas de que sus intereses, aunque no maximizados, se satisfarían de forma óptima apoyando a ese partido ${ }^{3}$.

4) Por lo tanto, la capacidad de cualquier partido de adquirir y mantener un papel dominante en el Gobierno, es decir, de alcanzar una posición

'Gramsci (1984): 1. «El Príncipe Moderno».

2 Gramsci (1984): 4. "Americanismo y Fordismo».

${ }^{3}$ Gramsci (1984): 1. «El Príncipe Moderno». 
begemónica, dependería de su capacidad de satisfacer, al menos, algunos de los intereses políticos de estos otros segmentos de la estructura social, es decir, los que no son esenciales ni están vinculados duraderamente a algún otro partido. La aceptación del papel hegemónico del partido dominante por parte de los miembros de dichas categorías alternativas guarda semejanza con el concepto de «legitimidad» de Weber ${ }^{4}$.

No está claro en Gramsci cómo se armonizaría la existencia de un partido hegemónico con la presencia de otros partidos, especialmente si uno u otros fueran a rivalizar por el poder. El título de su ensayo «El Príncipe Moderno" indica claramente que concibió un sistema de partido único donde, sin embargo, el partido hegemónico sería lo suficientemente flexible y abierto como para que la presencia de otros partidos fuera más una cuestión de negociación que de competencia.

La mayoría de los investigadores sociales han defendido que un sistema de estas características - Gobierno democrático de partido único- sólo podría perdurar si los partidos alternativos compitieran realmente por el papel hegemónico y si el número de partidos competidores fuera bastante reducido. Así, la legitimidad hegemónica como sistema político no parecería requerir una verdadera estructura multipartidista. $E$ incluso en un sistema realmente multipartidista, uno de los partidos podría perfectamente mantener una posición hegemónica durante un largo período de tiempo, como por ejemplo, en Suecia ${ }^{5}$.

Para este análisis tienen un interés especial tres características de esta concepción de las conexiones entre la DIT, el apoyo partidista y la existencia de una democracia multipartidista estable. El apoyo estructural de los partidos políticos rivales se considera más proclive a la estabilidad y la democracia cuando: a) existe un número relativamente pequeño de partidos importantes; $b$ ) cada uno de estos partidos tiene una clientela socioestructural específica; y $c$ ) la posición estructural de los diferentes partidos es suficientemente flexible para permitir la competencia por otros grandes segmentos de la población. Dicho sistema puede definirse como «legitimidad hegemónica», es decir, el partido en el poder responde en todo momento a los «intereses» de los segmentos de la población que no forman parte de sus elementos socioestructurales básicos; los partidos que se disputan el poder intentan expandir el margen socioestructural de sus apoyos.

Refiriéndonos ahora más específicamente a la División del Trabajo en

${ }^{4}$ Max Weber (1964): 324-424.

"Esta caracterización es similar a la que hace Sartori de «partido predominante», y no a la de "partido hegemónico» del mismo autor. Un sistema de partido predominante se configuraría al alcanzar ese partido la mayoría absoluta. En un sistema de partido hegemónico, por el contrario, los demás partidos actuarían como partidos «satélites" o subordinados, sin capacidad para desafiar esa hegemonía (Sartori, 1980: 160-164, 192-201, 230-238). 
el sistema político que denominamos legitimidad hegemónica, pueden concebirse los siguientes elementos que caracterizan el modelo de formación de los electorados de cada partido: a) una categoría o conjunto de categorías de la División del Trabajo que constituyen raíces duraderas para el partido político en cuestión, pero que, sin embargo, no son en sí mismas suficientes para asegurar la hegemonía; b) un conjunto de categorías de la División del Trabajo en las que los partidos mantienen raíces débiles, y cuyas fluctuaciones pueden ser decisivas para que cualquiera de los partidos rivales obtenga el poder. Es bastante probable que los primeros dos aspectos den lugar, a un tercero: c) una categoría o conjunto de categorías en las que un partido es rechazado.

Obviamente, el modelo que acabamos de describir puede ofrecer diversas variantes. Por ejemplo, el arraigo en una categoría de la División del Trabajo puede ser exclusivo de un partido o puede estar compartido con otro, especialmente cuando los dos presentan programas muy similares. Además, el grado de apoyo obtenido en una categoría puede variar para los diferentes partidos, no habiendo razón para suponer que exista simetría en este sentido. Lo mismo sucede con el grado de rechazo: aunque es probable que el fuerte apoyo recibido por un partido en una categoría esté correlacionado con el rechazo sufrido por el partido ideológicamente más distante de aquél, tampoco hay razón para suponer este tipo de simetría a priori. De hecho, algunos partidos pueden alcanzar el éxito contando con raíces débiles en un amplio espectro de posiciones de la División del Trabajo. Sin embargo, en nuestra hipótesis mantenemos que la existencia de la estructura básica de la legitimidad hegemónica que acabamos de presentar tiene algunas consecuencias importantes.

Sin la primera condición, es decir, un arraigo fuerte y estable, un partido no podría mantener una presencia competitiva duradera en la esfera política. No contaría con una base de apoyo que fuera relativamente segura. Sin la segunda, es decir, la capacidad de competir por categorías de la División del Trabajo que no constituyen arraigos fuertes para ninguno de los partidos, estaría condenado a representar un papel permanentemente minoritario, y nunca podría aspirar a alcanzar una posición hegemónica. En nuestra hipótesis, la tercera condición, es decir, la existencia de categorías que lo rechazan, funciona como la contrapartida de la primera. Limita las áreas de la División del Trabajo en las que puede competir dicho partido. Si la primera condición puede concebirse como un «suelo» electoral respecto al apoyo partidista, la tercera representa su «techo». Asimismo, creemos que allí donde el éxito electoral se logra sin el apoyo de una categoría central, es decir, en el caso en que un partido triunfa contando con raíces débiles en diversas categorías, cabría esperar, en base a la fragilidad de los apoyos recibidos, grandes dificultades para mantener esos resultados en elecciones sucesivas. Conviene observar que si existieran grupos con intereses muy poderosos aso- 
ciados a un partido que no reuniera las condiciones $a$ ) y/o $b$ ) durante un período de tiempo «razonable», la probabilidad de que dichos grupos recurrieran a algún tipo de dominación ilegítima aumentaría considerablemente.

\section{ESTRUCTURA SOCIAL Y PARTIDOS EN ESPAÑA}

\section{Dimensiones de la División del Trabajo}

En este estudio, el análisis de las variables socioestructurales está limitado a aquellas que miden aspectos de la División del Trabajo (DT) y especialmente al funcionamiento de dicbas variables respecto al mercado de trabajo. En futuras investigaciones se analizarán variables demográficas, tales como tamaño de hábitat y tamaño y composición de la familia, variables de estatus, como educación, y variables políticas, como la conciencia regional, etc.

Así como Gramsci se concentró en la División del Trabajo en la Industria («La hegemonía nace en la fábrica») ${ }^{6}$, Weber conceptualizó las categorías de la DT en el contexto de un mercado de trabajo completamente desarrollado. Lo más importante para este análisis es su distinción entre la posición con respecto al mercado de trabajo, es decir, la situación de mercado, y las posiciones dentro del mercado de trabajo ${ }^{7}$. La situación de mercado no sólo se refiere a si se compra o vende trabajo, sino también a las situaciones que limitan efectivamente las condiciones de cualquier transacción de mercado entre empresarios y asalariados. Un ejemplo de estas limitaciones lo constituye la distinción legal en España entre empleos permanentes (o fijos) $\mathrm{y}$ temporales, que implican distintas exenciones fiscales $\mathrm{y}$ ayudas estatales para la empresa.

Estos dos aspectos del mercado de trabajo, es decir, la situación de mercado y la posición en el mercado, constituyen dimensiones analíticamente diferentes de la DT. La situación de mercado tiene un carácter más amplio y, fundamentalmente, estima el grado y tipo de participación en el mercado. Por ejemplo, incluye categorías que, formalmente, no son parte del mercado, pero que, claramente, sí lo son de la división social del trabajo (como, por ejemplo, las amas de casa). Además, una proporción significativa de esta categoría (así como la totalidad de los jubilados) fueron parte del mercado de trabajo en un período anterior. Por último, esta dimensión también incluye a los desempleados, quienes, aun formando parte del mercado de trabajo, careccn de una posición en el mismo. Resumiendo, las categorías que constituyen la situación de mercado representan la División del Trabajo en la

6 A. Gramsci (1984): 291.

'M. Weber (1984): 181-184 y 250-254. 
Sociedad y proporcionan una estimación mucho más completa de las bases sociales del apoyo partidista.

La posición en el mercado, por el contrario, se limita a aquellos que, en la actualidad, tienen empleo. Esta variable nos permite medir la División Industrial del Trabajo (DIT). De este modo, podemos evaluar las consecuencias para el apoyo partidista del tipo y nivel de la posición ocupada dentro de la fuerza de trabajo. El estudio de ambos aspectos de la DT no sólo proporciona un análisis mucho más completo, sino que la comparación entre ellos respecto a las tendencias observadas en los apoyos partidistas revela diferencias importantes.

Como hipótesis general sostenemos que la estabilidad de la democracia partidista se maximiza cuando los diferentes partidos están arraigados de una forma coherente en ambos tipos de categorías: las de la DIT y las de la División del Trabajo en la Sociedad. Por ejemplo, si un partido está fuertemente arraigado entre los trabajadores industriales semicualificados (medido con una variable que estima la posición dentro del mercado), pero es débil entre los trabajadores con empleo utemporal» (medido con una variable que estima la situación de mercado) y si, además, una gran proporción de trabajadores semicualificados tiene un empleo temporal, su arraigo será bastante problemático y, pronosticaremos, susceptible de erosión.

Vamos a utilizar, también, una tercera dimensión de la División del Trabajo: el Sector Económico (o Rama de Actividad). Por lo general, el Sector Económico se define como una estimación de base muy amplia de las diferentes formas en que se organizan las distintas actividades económicas. Por ejemplo, el Sector Servicios generado por el sector privado de la economía se supone que incluye un gran número de organizaciones más bien pequeñas, con jerarquías de autoridad bastante atenuadas y con actividades laborales más bien homogéneas. En comparación, el Sector Industrial comprende muchas menos organizaciones y éstas son relativamente grandes, tienen jerarquías de autoridad extensas y tipos heterogéneos de actividades laborales.

No disponemos de observaciones directas que nos permitan probar si esta interpretación de los sectores es aplicable, o no, a la economía española. Sin embargo, hay algunas vías indirectas de investigar este problema. En nuestra muestra, el Sector Servicios de la empresa privada comprende el mayor número de propietarics no agrícolas, en torno a un 72 por 100. Esto confirma, en cierta manera, que muchas de las empresas en este sector tienen que ser pequeñas. También, comparado con el Sector Industrial, el Sector Servicios de la empresa privada comprende muchos menos trabajadores cualificados y semicualificados, pero muchos más no cualificados. En cierto sentido, esto confirma indirectamente la relativa homogeneidad de las actividades laborales en el Sector Servicios de la empresa privada.

Desde una perspectiva evolucionista, el Sector Económico a menudo se 
considera como una medida indirecta del desarrollo, expresando el paso de la extracción a la industria y de ésta a los servicios. Cuando lleguemos al análisis de esta variable veremos que se trata de una interpretación dudosa, al menos para la economía española.

En suma, el Sector Económico se define como el aspecto económico de la DT, cuando la economía se considera globalmente. Sólo si se acepta la perspectiva evolucionista que acabamos de comentar, tiene esta dimensión de la DT una relación específica con el mercado de trabajo. En dicho esquema, el tamaño comparativo de los sectores indicaría la magnitud y profundidad del mercado de trabajo.

Querríamos resaltar que, aunque creemos que estos factores son muy importantes, rechazamos fuertemente cualquier connotación determinista. De ninguna forma argumentamos que estas variables agoten las causas de «El milagro español», y no digamos las bases sociales del apoyo partidista.

\section{Los partidos políticos en la España contemporánea}

El sistema de partidos español se constituye en el período de la transición posterior a Franco. Existen abundantes estudios sobre este período, comprendido, aproximadamente, entre 1976 y $1982^{\circ}$. La mayoría de los observadores sitúan el final del período de la transición en las elecciones de 1982, con el surgimiento del PSOE como partido dominante. Al menos hasta esas elecciones legislativas, el sistema de partidos estuvo sujeto a considerables fluctuaciones organizativas, con la disolución de coaliciones anteriores (como la UCD), la formación de nuevos partidos (CDS) y la desintegración y reconstrucción de partidos tradicionales. El sistema de partidos derivado de las elecciones de 1982 ha permanecido razonablemente estable, presentándose una configuración similar en las elecciones generales de 1986. La única variación consistió en la aparición de IU como una coalición entre el PCE y algunos pequeños grupos escindidos de la izquierda.

A nivel nacional, este sistema consiste en cuatro partidos principales: de derecha a izquierda, el PP (Partido Popular), el CDS (Centro Democrático y Social), el PSOE (Partido Socialista Obrero Español) y la coalición IU (Izquierda Unida). Por otra parte, habría que añadir los subsistemas de partidos regionales, que adquieren una especial trascendencia en Galicia, Cataluña y el País Vasco.

Desde las elecciones de 1986 , el proceso de cambio se ha ido desacelerando y puede caracterizarse más como un proceso de consolidación que de transformación. Por ejemplo, el «cambio» reciente más importante, como es

${ }^{8}$ Véanse, por ejemplo, algunos de los trabajos citados al final de este artículo y el nú. mero 68 de la revista Sistema (1985), que contiene una extensa referencia bibliográfica sobre la transición democrática española. 
la modificación del nombre de AP, la vuelta de su fundador y líder más carismático, la absorción por este partido de algunos otros de centro-derecha, tiene que considerarse más como un proceso de consolidación de un partido importante que como un cambio básico en el sistema de partidos ${ }^{9}$.

\section{METODOLOGIA}

\section{La muestra y la Variable Dependiente}

El grupo de partidos que compite a nivel nacional, PP, CDS, PSOE e IU, junto con las abstenciones, forman nuestra variable dependiente. Tal y como se verá más adelante, la discusión sobre esta variable requiere una discusión acerca de la muestra.

Los resultados electorales de estos cuatro partidos, representados por el porcentaje de voto alcanzado a nivel nacional en las elecciones generales de 1986, así como el recuerdo de voto, tal y como se refleja en los resultados de nuestra encuesta, se presentan en la tabla I:

\section{TABLA I}

Resultados de las Elecciones de 1986 (Porcentajes)

\begin{tabular}{|c|c|c|c|}
\hline \multirow[b]{3}{*}{ 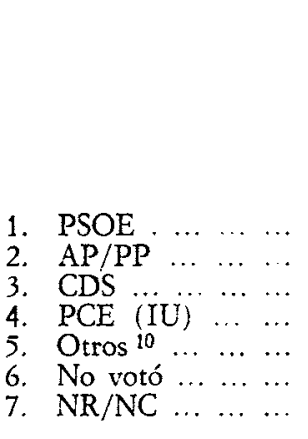 } & \multirow[t]{2}{*}{$\begin{array}{l}\text { RESULTADOS NACIO- } \\
\text { NALES CENSALES }\end{array}$} & \multicolumn{2}{|c|}{$\begin{array}{c}\text { RESULTADOS NACIONALES } \\
\text { MUESTRALES }\end{array}$} \\
\hline & & $\begin{array}{l}\text { Totales marginales } \\
\text { de la encuesta }\end{array}$ & $\begin{array}{l}\text { Datos empleados } \\
\text { en nuestro estudio }\end{array}$ \\
\hline & $\begin{array}{r}30,7 \\
18,7 \\
6,4 \\
3,5 \\
10,7 \\
30,6 \\
-\end{array}$ & $\begin{array}{r}39 \\
11 \\
7 \\
4 \\
4 \\
18 \\
17\end{array}$ & $\begin{array}{r}41,90 \\
11,55 \\
7,29 \\
3,75 \\
5,30 \\
13,02 \\
17,16\end{array}$ \\
\hline Total ... ... & 99,8 & 100 & 100,00 \\
\hline $\begin{array}{llll}N & \ldots & \ldots & \ldots\end{array}$ & 28.975 .743 & 27.377 & 25.395 \\
\hline
\end{tabular}

9 En el momento de redactarse este artículo, aún no había sido elegido José María Az. nar como primer candidato del PP ni se habían celebrado las elecciones generales del 29 de octubre. No obstante, creemos que los resultados obtenidos por las cuatro fuerzas políticas principales no restan validez a nuestro análisis, que, por el contrario, puede contribuir a esclarecer la dirección e intensidad de los cambios producidos.

${ }^{10} \mathrm{La}$ categoría otros incluye un nutrido número de partidos regionales. 
Las tres columnas difieren entre sí como sigue: la primera representa el porcentaje real del voto de cada partido a nivel nacional, sobre la base del Censo. Obviamente, constituye la mejor información y es la única que no cstá basada en la memoria del entrevistado. La segunda columna recoge los resultados del conjunto de la muestra. Los porcentajes están ajustados mediante ponderación para compensar las diferencias censales de población entre provincias. La tercera columna recoge el conjunto de datos que utilizaremos en nuestro análisis. Difiere de la anterior por haberse eliminado a aquellos entrevistados que no tenían edad para votar cuando se celebraron las elecciones de 1986 (dieciséis y diecisiete años).

La Tabla I plantea dos cuestiones importantes. La primera es la amplia diferencia en el porcentaje de los votos recibidos por cada partido, con un rango que oscila entre el 3,5 y el 30,7 por 100 para los cuatro más importantes. La inclusión, en nuestro análisis, de partidos que reciben un porcentaje relativamente pequeño de los votos (CDS e IU), quizá merezca una explicación. Responde, en primer lugar, a que no se descarta la posibilidad de ciertos cambios significativos en la actual distribución de fuerzas entre los cuatro partidos, y, en segundo lugar, a que esos partidos definen con bastante exactitud el espectro político español (derecha-izquierda) a nivel nacional ${ }^{11}$. Cambios estructurales o cambios en la estrategia de los partidos podrían provocar modificaciones en el mapa electoral. En definitiva, se les supone la capacidad de competir entre sí, siendo uno de nuestros objetivos el determinar en qué posiciones de la estructura social se refuerza o debilita esa competencia.

La segunda cuestión a la que aludíamos antes es el gran sesgo en las estimaciones de los porcentajes de votos recibidos, tanto por AP/PP (infraestimado en un 7 por 100), como por el PSOE (sobre-estimado en un 8 y un 11 por 100). El sesgo en la estimación del porcentaje de voto recibido por AP/PP y el PSOE a partir del recuerdo de voto, es un problema habitual en los estudios llevados a cabo por el CIS y otros Institutos de Opinión.

Desde las elecciones de 1986, y refiriéndonos a los estudios realizados por el CIS desde esa fecha, el promedio del conjunto de estimaciones basadas en el recuerdo de voto es, en relación al PSOE, de un 37 por 100, o una sobre-estimación del 6,3 por 100, con un rango entre el 33 y el 41 por 100 . Con respecto a $\mathrm{AP} / \mathrm{PP}$, el sesgo se manifiesta en un promedio de voto del 11,9 por 100 , o una infra-estimación del 6 por 100 , con un rango entre el 10 y el 15 por 100 . El problema es el siguiente: ¿representan estos sesgos una distorsión más o menos deliberada del voto por parte de los entrevistados o, por el contrario, cabe achacarlos a la manera en que se diseñan y seleccionan las muestras?

La muestra está diseñada de forma poli-etápica aleatoria, estratificada por

$"$ A la fuerza electoral de un partido, medida en número de escaños, hay que añadir, según Sartori, su capacidad de negociación para montar una «coalición viable» ( «las que son ideológicamente consonantes y permisibles»). G. Sartori (1980): 155-156. 
conglomerados, es decir, por región, provincia, tamaño de hábitat, sección electoral y rutas aleatorias. El entrevistador selecciona la vivienda por un método aleatorio simple: una de cada tres. El único punto en el que puede ejercer cierta discrecionalidad es en la selección de la persona a entrevistar, para lo que tiene asignadas cuotas por sexo y edad.

Una interpretación común, compartida por numerosos expertos en estudios de opinión, atribuye la responsabilidad del sesgo a este paso final. Durante el proceso de búsqueda de las personas que cumplen los requisitos fijados de sexo y edad, el entrevistador tendría más facilidad para encontrar y completar la entrevista a votantes del PSOE. Lo contrario ocurriría con los votantes de AP/PP. Varias razones se han aducido al respecto: que los votantes del PSOE viven en hogares más fácilmente accesibles (sin portero, por ejemplo), o que están más dispuestos a permanecer el tiempo necesario para la realización de la entrevista. Desde luego, tales interpretaciones son especulativas y convenientes. A nosotros no nos convencen suficientemente, ya que, al menos en lo que respecta al CIS, los entrevistadores están extremadamente bien formados y realizan su trabajo desde hace varios años. Por lo tanto, pueden considerarse profesionales en su parcela de actuación.

Sin embargo, tampoco hay evidencia sistemática que apoye la explicación alternativa de que los entrevistados falseen sus respuestas y/o las olviden de forma sistemática. Esa falta de evidencia se refiere expresamente a la ausencia de asociación entre la magnitud del sesgo por posible erosión de la memoria y la fecha de realización de los estudios, al no producirse un incremento del mismo a medida que los estudios se alejan de la convocatoria electoral.

La misma ausencia de relación entre la fecha de la encuesta y la magnitud del sesgo nos conduce a desechar un posible efecto de «corriente», una suerte de tendencia a subirse al carro del ganador, que se manifestaría en un falseamiento del voto realmente emitido en las elecciones, con el resultado de un incremento del apoyo, en este caso, al PSOE. Si éste fuera el caso, sería de esperar una disminución del sesgo con el correr del tiempo. Más recientemente, ese efecto tendría que haber disminuido como resultado del creciente conflicto entre los sindicatos (cuyos miembros representan una proporción significativa entre los votantes del PSOE) y el Gobierno.

Explicar el sesgo en la estimación del apoyo electoral a los dos principales partidos es importante para este estudio, ya que tratamos de analizar las características de sus votantes, en lugar de predecir el voto. Dicho de otro modo, si los entrevistados votaron tal y como manifiestan haberlo hecho en sus respuestas en la encuesta, entonces el plan de análisis que aquí planteamos tendrá consistencia, incluso si la proporción de quienes votaron por los distintos partidos está sesgada.

A nuestro entender, un gran número de factores entran en juego. Nos inclinamos a creer que una parte de los entrevistados que apoyan electoralmente a partidos importantes de la oposición, no involucrados en tareas de 
gobierno (el PP, por ejemplo), escogen desproporcionadamente las opciones «No recuerda» y «No contesta». Esta opción no sólo infra-estima el apoyo al PP y a los Partidos Regionales, sino que, debido a esa disminución, sobreestima el voto al PSOE. Hay razones que pueden provocar este falseamiento. Por ejemplo, hace poco más de diez años, en España resultaba cuando menos imprudente referir abiertamente el apoyo a un partido opositor. Es posible que, a pesar de los profundos cambios del sistema político, viejos hábitos, ahora ubicados en otra franja del espectro político, sobrevivan en algunos segmentos de la población.

Reconocemos que esta explicación resulta conveniente para el análisis que sigue. Permite creer que las respuestas de los entrevistados reflejan fielmente sus opciones de voto, desvirtuando, por el contrario, la magnitud del apoyo a los distintos partidos. Sin embargo, ninguna de las posibles explicaciones puede desecharse. No hay duda de que todas ellas están implicadas de una u otra manera.

La abstención. Las categorías «No recuerda» y «No contesta» han sido omitidas en nuestro análisis por la dificultad de interpretar el significado de estas respuestas. Pueden reflejar auténticas lagunas en la memoria de los votantes sobre su opción de voto o una dificultad para recordar incluso si se votó o no, o un deseo de esconder por qué partido se votó.

Como señalamos antes, hemos decidido añadir la abstención como una, categoría más de nuestra variable dependiente. Hay varias razones que respaldan esta decisión. En primer lugar, es una respuesta más homogénea y, por lo tanto, más fácilmente interpretable. En segundo lugar, aunque se concentra en cierto modo en las categorías de estatus más bajo, está mucho más extendida entre el rango de categorías estructurales que la categoría "No recuerda». En consecuencia, resulta más accesible para una interpretación como la nuestra, cuyo enfoque central es el apoyo partidista y la posición estructural. En cierto sentido, tratamos la abstención como si de un quinto pseudopartido se tratara.

En definitiva, la variable dependiente en nuestro estudio está formada por cinco categorías o «partidos»: 1) AP/PP; 2) CDS; 3) PSOE; 4) IU; 5) ABSTENCION. La proporción marginal de cada una de estas categorías se presentó más arriba, en la tabla $I$.

\section{Las variables independientes}

Hay tres variables independientes: 1) Situación laboral; 2) Ocupación; 3) Rama de actividad. Las presentamos en el mismo orden en que serán analizadas. La variable Situación laboral se utiliza para evaluar la situación 
respecto al mercado de trabajo (situación de mercado), es decir, los aspectos más sociales de la División del Trabajo. La Ocupación, para medir la ubicación dentro de la División Industrial del Trabajo, o la posición en el mercado, y la Rama de Actividad, para evaluar los efectos relativos al sector económico.

La variable Situación laboral contiene las siguientes categorías:

1) Trabajadores por cuenta propia;

2) Trabajadores fijos por cuenta ajena;

3) Trabajadores eventuales por cuenta ajena;

4) Empleados como ayuda familiar;

5) Parados que trabajaron antes;

6) Jubilados y/o pensionistas;

7) Parados sin empleo anterior;

8) Estudiantes;

9) Trabajo doméstico no remunerado.

Desde luego, la posición en el mercado podría estimarse mucho mejor mediante el análisis de la relación entre las variables ocupación y salario. Desgraciadamente, los datos con los que trabajamos no incluyen información sobre los ingresos de los entrevistados. No obstante, puesto que la Ocupación está recogida con mucho detalle, la emplearemos para estimar este aspecto de la División Industrial del Trabajo (DIT).

Las categorías ocupacionales utilizadas en este análisis provienen de un largo y arduo trabajo consistente en clasificar cada una de las ocupaciones recogidas a tres dígitos ( $y$, en ocasiones, a cinco dígitos) en el Diccionario Español de Ocupaciones. La teoría en la que nos basamos para hacerlo, proviene, en lo fundamental, de Weber ${ }^{12}$. Por lo tanto, las categorías finales que aquí se presentan reflejan actividades homogéneas que comparten una misma posición en el mercado. El procedimiento seguido para construir esta clasificación lo describimos en detalle en La clasificación de ocupaciones en España (CIS, manuscrito, junio 1989).

El esquema final resultante contiene ocho categorías básicas, dentro de las cuales se han anidado subcategorías adicionales. En concreto, son las siguientes:

1. Profesionales, semiprofesionales y técnicos:

A) Científicos, ingenieros y otros profesionales tradicionales.

B) Técnicos.

C) Profesionales subordinados (semiprofesionales).

12 M. Weber (1964): 250-254. 
2. Directivos, propietarios y administradores:

A) Grandes propietarios y directivos.

B) Pequeños propietarios y administradores de nivel medio.

3. Administradores de nivel inferior.

4. Artesanos.

5. Pequeños propietarios agrícolas.

6. Supervisores, capataces y trabajadores cualificados:
A) De cuello blanco.
B) De cuello azul.

7. Trabajadores semicualificados:
A) De cuello blanco.
B) De cuello azul.

8. Trabajadores no cualificados:
A) De cuello blanco.
B) De cuello azul.

La variable Rama de Actividad presenta las siguientes categorías:

1) Agricultura, ganadería, pesca.

2) Industria.

3) Construcción.

4) Servicios (empresas privadas).

5) Servicios (Administraciones Públicas).

\section{Metodología utilizada en el análisis de los datos}

Puesto que tanto las variables independientes como la variable dependiente. están medidas a nivel nominal, hemos elegido, obviamente, un tipo de análisis estadístico apropiado para esos datos. Además, estamos especialmente interesados en comparar y contrastar las diferentes categorías de las variables independientes a lo largo del vector de partidos que conforma nuestra variable dependiente. Dicho de otro modo, necesitamos un estadístico que permita realizar comparaciones entre un gran número de celdillas individuales ${ }^{13}$.

Hemos optado por calcular el Gi-cuadrado para cada tabla de contingencia, lo que, esencialmente, constituye un test de independencia entre variables.

${ }^{13}$ B. S. Everitt (1977): 41. 
Dada la naturaleza de los datos y el tamaño de la muestra, casi todos los tests resultaron positivos, lo que nos permitió rechazar la hipótesis nula sobre la no pendencia, procedimos a calcular las particiones del Gi-cuadrado, con el fin existencia de asociación entre las variables. Una vez contrastada aquella indede obtener las frecuencias ajustadas de cada celdilla en cada una de las tablas. Las fórmulas utilizadas son las siguientes:

1) La frecuencia o valor absoluto de cada celdilla, $n_{i j}$.

2) La frecuencia esperada, $E_{i j}$, donde $E_{i j}$ se calcula mediante la fórmula: $n_{i} \cdot n_{. j} / N$.

3) Los residuos, $O_{i j}-E_{i j}$, donde $O_{i j}$ es equivalente a $n_{i j}$.

4) Los residuos estandarizados, $e_{i j}$, obtenidos a partir de: $e_{i j}=\left(n_{i j}-E_{i j}\right) / \sqrt{E_{i j}}$.

5) Los residuos ajustados, $d_{i j}$, derivados de la fórmula $d_{i j}=e_{i j} / \sqrt{v_{i j}}$, donde $v_{i j}$ es una estimación de la varianza de $e_{i j}, \mathrm{y}$ está dada por: $v_{i j}=\left(1-n_{i .} / N\right)\left(1-n_{. j} / N\right)$.

Los residuos ajustados ${ }^{14}$ tienen una distribución aproximadamente normal, de manera que con valores superiores a 1,96 son estadísticamente significativos al nivel 0,05 .

El análisis conlleva tres tipos de presentación de los datos. Empezaremos presentando un conjunto de tablas que recogen los datos en su forma más elemental, absolutos y porcentajes, acompañado de gráficos que muestran las distribuciones porcentuales marginales de cada variable. El propósito de estas tablas es el de introducir las variables y ofrecer al lector el valor absoluto y el tamaño relativo de cada categoría para cada una de las variables. El segundo grupo de tablas analiza los datos utilizando la bondad del ajuste del Gi-cuadrado para probar el modelo de independencia, así como los residuos ajustados de cada celdilla para estimar la profundidad del apoyo que disfruta cada partido en cada una de las categorías.

La interpretación de estas tablas constituye el análisis central de las ideas que se presentaron antes sobre las relaciones entre la situación respecto al mercado de trabajo, la posición en el mercado y la rama de actividad, por un lado, y el apoyo electoral y la democracia de partidos, por otro. La tercera forma en que se presentan los datos es mediante diagramas. Cada uno de ellos muestra los residuos ajustados de cada celdilla para los cuatro partidos por cada dimensión de la estructura social, seguido de un diagrama que recoge esa misma información, pero limitada, ahora, a los dos partidos principales, el PSOE y el PP.

Como ya hemos comentado, los residuos ajustados se utilizarán como una estimación del nivel de apoyo dado a un partido por una determinada ubicación dentro de la estructura social, representada por aquella celdilla.

i4 Haberman (1973). 
Los diagramas que se presentan permiten comparar esas tendencias de apoyo observadas para cada uno de los partidos, es decir: dónde se presentan las mayores diferencias, dónde están los partidos mejor capacitados para competir, etc. Considerando conjuntamente los residuos ajustados y sus variaciones relativas, tal y como aparecen en los diagramas, se puede evaluar, al menos parcialmente, el grado de legitimidad hegemónica estimado por los resultados de las elecciones generales de 1986.

\section{LOS DATOS}

Situación de mercado: la División del Trabajo en la Sociedad

Como ya se ha dicho, presentaremos primero los gráficos y las tablas de absolutos y porcentajes más elementales para centrarnos, después, en las tablas y diagramas que recogen los residuos ajustados (RA). Por lo tanto, el gráfico 1 y la tabla II presentan los datos más elementales sobre la Situación Laboral y el Recuerdo de Voto, mientras que la tabla IIA recoge los RA para los mismos datos.

Es importante señalar que, en lo que respecta a su tamaño absoluto y relativo, las categorías de la muestra no son, obviamente, representativas de la población, ni tan siquiera de la muestra original. Algunos miles de casos han sido omitidos en razón de la forma en que se construyeron las variables. Además, nuestros códigos son a menudo bastante diferentes de los utilizados por el Instituto Nacional de Estadística o el Anuario de Estadísticas Laborales. Aquí vamos a limitarnos a explicar las diferencias entre la muestra utilizada y la original.

Obviamente, la primera característica de la tabla II es la reducción en el tamaño del $\mathrm{N}$. Hay tres razones que explican esa considerable variación respecto a los 25.395 entrevistados que aparecen en la tabla I, y que afectan también al resto de tablas que presentaremos. La primera, que ya hemos señalado, es la ponderación aplicada para compensar las diferencias provinciales de la muestra respecto al Universo del que fue extraída. Aunque estos coeficientes de ponderación no afectan al $\mathrm{N}$ total, sí introducen pequeñas variaciones. Además, esas variaciones interaccionan y aumentan con la omisión de categorías, que es la segunda razón para aquella reducción. Para empezar, las mismas categorías del recuerdo de voto omitidas en la tercera columna de la tabla I están ausentes en el resto de las tablas: los que tenían dieciséis y diecisiete años antes de junio de 1986, las categorías «No Recuerda» y «No contesta» y los «Otros Partidos». Además, y ésta es la última razón, también se han omitido categorías en las variables independientes, provocando considerables variaciones. En la tabla II, por ejemplo, no se incluyen 


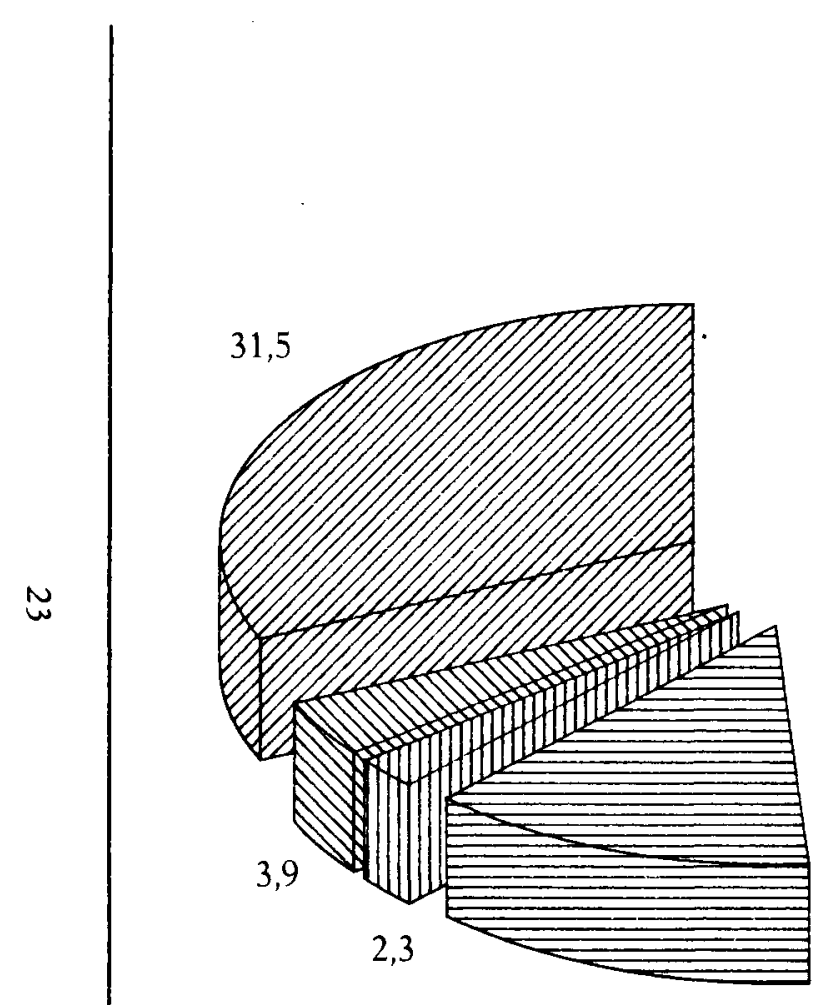

$.13,2$

\section{GRAFICO 1}

Situación laboral

(Distribución porcentual)

\section{2,8}

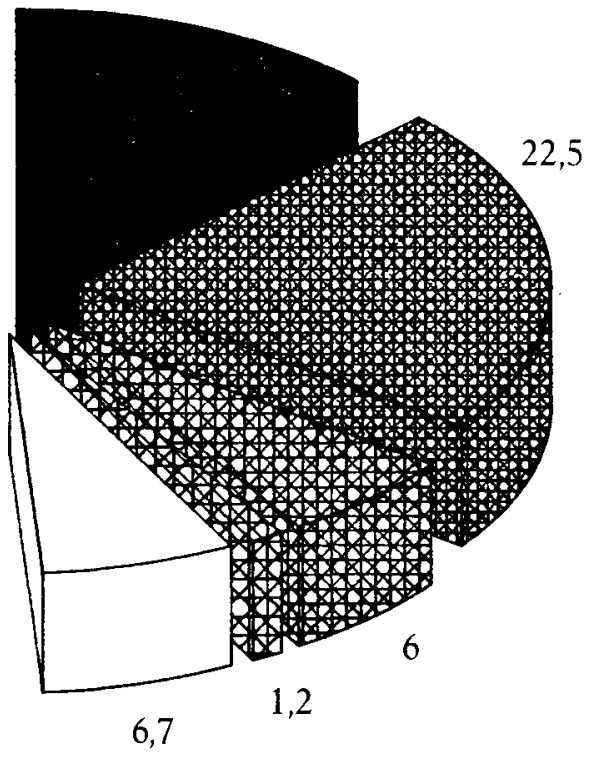

\begin{tabular}{|l|}
\hline CUENTA \\
PROPIA \\
ASALARIADO \\
FIJO \\
ASALARIADO \\
EVENTUAL \\
AYUDA \\
FAMILIAR \\
$\square$ PARADO \\
JUBILADO \\
PENSIONISTA \\
BUSCA \\
PRIMER \\
EMPLEO \\
ESTUDIANTE
\end{tabular}

$\mathrm{N}=19.093$
ESTUDIANTE

$\square$ SUS

LABORES 
TABLA II

\section{Situación laboral}

Trabaja por cuenta propia

Absolutos ...

$\begin{array}{lllll}\% & \text { columna } & \ldots & \ldots & \ldots \\ \% & \ldots & \ldots\end{array}$

$\%$ fila $\ldots \ldots \ldots c c c c$

$\%$ tabla $\ldots \begin{array}{llll} & \ldots & \ldots & \ldots\end{array}$

Asalariado fijo

Absolutos $\ldots \ldots \ldots \ldots$

$\%$ columna $\ldots . . . . .$.

$\%$ fila $\ldots \ldots \ldots c c c c c$

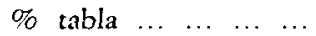

Asalariado eventual

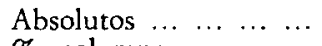

$\%$ columna $\ldots \ldots+\ldots$

$\%$ fila ................

$\begin{array}{llllll}\% & \text { tabla } & \ldots & \ldots & \ldots & \ldots\end{array}$

Ayuda familiar

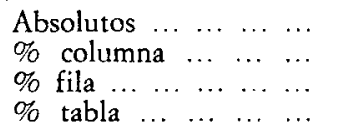

Parado y ha trabajado antes

$\begin{array}{lllll}\text { Absolutos } & \ldots & \ldots & \ldots & \ldots\end{array}$

$\%$ columna $\ldots \ldots$... $\ldots$

$\%$ fila $\ldots . . . . . . . . . .$.

$\%$ tabla $\ldots \begin{array}{llll}\% & \ldots & \ldots & \ldots\end{array}$

Jubilado, pensionista, etc.
Absolutos ... . . . ... ...
$\%$ columna $\ldots \ldots \ldots$
$\%$ fila $\ldots \ldots \ldots \ldots$
$\begin{array}{llllll}\% & \text { tabla } & \ldots & \ldots & \ldots & \ldots\end{array}$
Parado y busca primer empleo

Absolutos ....

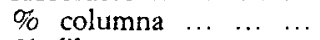

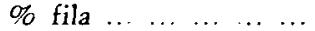

$\%$ tabla

Estudiante

\begin{tabular}{|c|c|c|c|c|c|c|}
\hline 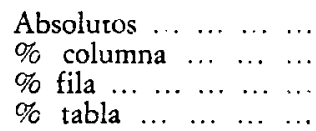 & $\begin{array}{r}86 \\
3,1 \\
11,6 \\
0,4\end{array}$ & $\begin{array}{r}62 \\
3,5 \\
8,4 \\
0,3\end{array}$ & $\begin{array}{r}269 \\
2,6 \\
36,4 \\
1,4\end{array}$ & $\begin{array}{l}62 \\
6,7 \\
8,4 \\
0,3\end{array}$ & $\begin{array}{r}260 \\
7,7 \\
35,2 \\
1,4\end{array}$ & $\begin{array}{r}739 \\
3,9 \\
100,0 \\
3,9\end{array}$ \\
\hline
\end{tabular}

$\begin{array}{rrrrrr}585 & 292 & 1.065 & 75 & 418 & 2.435 \\ 21,0 & 16,4 & 10,4 & 8,1 & 12,3 & 12,8 \\ 24,0 & 12,0 & 43,7 & 3,1 & 17,2 & 100,0 \\ 3,1 & 1,5 & 5,6 & 0,4 & 2,2 & 12,8\end{array}$

$\begin{array}{rrrrrr}469 & 410 & 2.443 & 332 & 643 & 4.298 \\ 16,8 & 23,0 & 23,9 & 35,8 & 19,0 & 22,5 \\ 10,9 & 9,5 & 56,8 & 7,7 & 15,0 & 100,0 \\ 2,5 & 2,1 & 12,8 & 1,7 & 3,4 & 22,5\end{array}$

$\begin{array}{rrrrrr}87 & 61 & 662 & 92 & 248 & 1.150 \\ 3,1 & 3,4 & 6,5 & 9,9 & 7,3 & 6,0 \\ 7,6 & 5,3 & 57,6 & 8,0 & 21,6 & 100,0 \\ 0,5 & 0,3 & 3,5 & 0,5 & 1,3 & 6,0\end{array}$

$\begin{array}{rrrrrr}52 & 21 & 108 & 8 & 34 & 224 \\ 1,9 & 1,2 & 1,1 & 0,9 & 1,0 & 1,2 \\ 23,2 & 9,5 & 48,4 & 3,8 & 15,1 & 100,0 \\ 0,3 & 0,1 & 0,6 & 0,0 & 0,2 & 1,2\end{array}$

$\begin{array}{rrrrrr}90 & 80 & 720 & 95 & 293 & 1.278 \\ 3,2 & 4,5 & 7,1 & 10,2 & 8,6 & 6,7 \\ 7,1 & 6,3 & 56,4 & 7,4 & 22,9 & 100,0 \\ 0,5 & 0,4 & 3,8 & 0,5 & 1,5 & 6,7\end{array}$

$\begin{array}{rrrrrr}429 & 180 & 1.459 & 94 & 359 & 2.521 \\ 15,4 & 10,2 & 14,3 & 10,1 & 10,6 & 13,2 \\ 17,0 & 7,2 & 57,9 & 3,7 & 14,2 & 100,0 \\ 2,2 & 0,9 & 7,6 & 0,5 & 1,9 & 13,2\end{array}$

$\begin{array}{rrrrrr}36 & 37 & 198 & 37 & 132 & 442 \\ 1,3 & 2,1 & 1,9 & 4,0 & 3,9 & 2,3 \\ 8,1 & 8,5 & 45,0 & 8,4 & 30,0 & 100,0 \\ 0,2 & 0,2 & 1,0 & 0,2 & 0,7 & 2,3\end{array}$

RECUERDO VOTO GENERALES DEL 86

\begin{tabular}{l}
$\begin{array}{c}A P-P D P \\
P L\end{array}$ CDS PSOE IU \\
\hline
\end{tabular}


TABLA II (Continuación)

\begin{tabular}{|c|c|c|c|c|c|c|}
\hline & \multicolumn{5}{|c|}{ RECUERDO VOTO GENERALES DEL 86} & \multirow[b]{2}{*}{ Total } \\
\hline & $\begin{array}{c}A P \cdot P D P \\
P L\end{array}$ & $C D S$ & PSOE & $I U$ & $\begin{array}{l}\text { Absten- } \\
\text { cionistas }\end{array}$ & \\
\hline \multicolumn{7}{|l|}{ Sus labores } \\
\hline Absolutos $\ldots \ldots \ldots$ & 954 & 633 & 3.288 & 134 & 997 & 6.007 \\
\hline$\%$ columna $\ldots \ldots \ldots$ & 34,2 & 35,6 & 32,2 & 14,4 & 29,5 & 31,5 \\
\hline 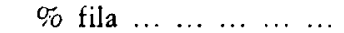 & 15,9 & 10,5 & 54,7 & 2,2 & 16,6 & 100,0 \\
\hline $\begin{array}{cccccc}\% & \text { tabla } & \ldots & \ldots & \ldots & \ldots\end{array}$ & 5,0 & 3,3 & 17,2 & 0,7 & 5,2 & 31,5 \\
\hline \multicolumn{7}{|l|}{ Total } \\
\hline Absolutos $\ldots \ldots \ldots$ & 2.789 & 1.777 & 10.214 & 929 & 3.384 & 19.093 \\
\hline$\%_{o}$ columna $\ldots \ldots \ldots$ & 100,0 & 100,0 & 100,0 & 100,0 & 100,0 & 100,0 \\
\hline 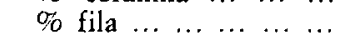 & 14,6 & 9,3 & 53,5 & 4,9 & 17,7 & 100,0 \\
\hline 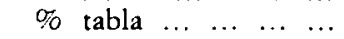 & 14,6 & 9,3 & 53,5 & 4,9 & 17,7 & 100,0 \\
\hline
\end{tabular}

TABLA IIA

\begin{tabular}{|c|c|c|c|c|c|c|}
\hline & \multicolumn{5}{|c|}{ RECUERDO VOTO GENERALES DEL 86} & \multirow[b]{2}{*}{ Total } \\
\hline & $\begin{array}{c}A P-P D P \\
P L\end{array}$ & CDS & PSOE & IU & $\begin{array}{l}\text { Absten- } \\
\text { cionistas }\end{array}$ & \\
\hline \multicolumn{7}{|l|}{ Situación laboral } \\
\hline \multicolumn{7}{|l|}{ Trabaja por cuenta propia } \\
\hline Absolutos $\ldots \ldots \ldots \ldots$ & 585 & 292 & 1.065 & 75 & 418 & 2.435 \\
\hline Frecuencia esperada ... & 355,7 & 226,7 & $1.302,7$ & 118,5 & 431,6 & 2.435 \\
\hline Residuos ... ... ... & 229,8 & 65,5 & $-238,1$ & $-43,2$ & $-13,9$ & 0 \\
\hline Residuos estandarizados & 12,2 & 4,3 & $-6,6$ & $-4,0$ & $-0,7$ & 一 \\
\hline Residuos ajustados . ... & 14,1 & 4,9 & $-10,4$ & $-4,4$ & $-0,8$ & - \\
\hline \multicolumn{7}{|l|}{ Asalariado fijo } \\
\hline Absolutos ... & 469 & 410 & 2.443 & 332 & 643 & 4.298 \\
\hline Frecuencia esperada ... & 627,7 & 400,0 & $2.299,0$ & 209,2 & 761,7 & 4.298 \\
\hline Residuos $\ldots \ldots \ldots \ldots$ & $-158,6$ & 9,6 & 144,2 & 123,1 & $-118,3$ & 0 \\
\hline Residuos estandarizados & $-6,3$ & 0,5 & 3,0 & 8,5 & $-4,3$ & - \\
\hline Residuos ajustados . ... & $-7,8$ & 0,6 & 5,0 & 9,9 & $-5,4$ & - \\
\hline \multicolumn{7}{|l|}{ Asalariado eventual } \\
\hline Absolutos $\ldots \ldots \ldots$ & 87 & 61 & 662 & 92 & 248 & 1.150 \\
\hline Frecuencia esperada ... & 168,0 & 107,1 & 615,4 & 56,0 & 203,9 & 1.150 \\
\hline $\begin{array}{lllll}\text { Residuos } & \ldots & \ldots & \ldots & \ldots\end{array}$ & $-80,9$ & $-46,1$ & 47,0 & 35,8 & 44,2 & 0 \\
\hline Residuos estandarizados & $-6,2$ & $-4,5$ & 1,9 & 4,8 & 3,1 & - \\
\hline Residuos ajustados . ... & $-7,8$ & $-4,8$ & 2,9 & 5,1 & 3,5 & 一 \\
\hline \multicolumn{7}{|l|}{ Ayuda familiar } \\
\hline Absolutos $\ldots \ldots \ldots \ldots$ & 52 & 21 & 108 & 8 & 34 & 224 \\
\hline Frecuencia esperada ... & 32,7 & 20,8 & 119,7 & 10,9 & 39,7 & 224 \\
\hline $\begin{array}{lllll}\text { Residuos } & \ldots & \ldots & \ldots & \ldots\end{array}$ & 19,2 & 0,5 & $-11,4$ & $-2,5$ & $-5,9$ & 0 \\
\hline Residuos estandarizados & 3,4 & 0,1 & $-1,0$ & $-0,8$ & $-0,9$ & - \\
\hline Residuos ajustados .... & 3,7 & 0,1 & $-1,5$ & $-0,8$ & $-1,0$ & - \\
\hline
\end{tabular}


TABLA IIA (Continuación)

\section{RECUERDO VOTO GENERALES DEL 86}

\begin{tabular}{rrrrrr}
\hline $\begin{array}{c}\text { AP-PDP } \\
P L\end{array}$ & CDS & PSOE & IU & $\begin{array}{c}\text { Absten- } \\
\text { cionistas }\end{array}$ & Total \\
& & & & & \\
90 & 80 & 720 & 95 & 293 & 1.278 \\
186,6 & 118,9 & 683,6 & 62,2 & 226,5 & 1.278 \\
$-94,4$ & $-38,8$ & 36,7 & 32,5 & 66,1 & 0 \\
$-7,1$ & $-3,6$ & 1,4 & 4,1 & 4,4 & - \\
$-7,9$ & $-3,9$ & 2,1 & 4,4 & 5,0 & -
\end{tabular}

Jubilado, pensionista, etc.

Absolutos ............

Frecuencia esperada ...

Residuos ... .........

Residuos estandarizados

Residuos ajustados . ...

Parado y busca primer empleo

Absolutos ............

Frecuencia esperada ...

Residuos $\ldots$
Residuos estandarizados

Residuos ajustados ....

Estudiante

Absolutos ............

Frecuencia esperada ...

Residuos $\ldots \ldots$.......

Residuos estandarizados

Residuos ajustados ....

Sus labores

Absolutos ............

Frecuencia esperada ...

Residuos ... ... ... ...

Residuos estandarizados

Residuos ajustados . ...

Total

Absolutos ... . . . . . .

Frecuencia esperada ...

Residuos ... ... ... ...

Residuos estandarizados

Residuos ajustados . .

$\begin{array}{rr}1.459 & 94 \\ 1.348,5 & 122,7 \\ 110,7 & -29,0 \\ 3,0 & -2,6 \\ 4,7 & -2,9\end{array}$

359

446,8

$-4,2$

$-4,9$
$-88,0$

$\begin{array}{rr}37 & 132 \\ 21,5 & 78,3 \\ 15,7 & 54,1 \\ 3,4 & 6,1 \\ 3,5 & 6,8\end{array}$

$\begin{array}{rr}62 & 260 \\ 36,0 & 130,9\end{array}$

$26,3 \quad 129,4$

$4,4 \quad 11,3$

$4,6 \quad 12,7$
395,2

$-126,4$

$-6,4$

$\begin{array}{rr}954 & 633 \\ 877,3 & 559,1 \\ 77,1 & 74,3 \\ 2,6 & 3,1 \\ 3,4 & 4,0\end{array}$

3.288
$3.213,4$
75,0
1,3
2,3

\section{4}

997

$1.064,7$

$-67,7$

$-2,1$

$\begin{array}{rr}292,4 & 1.064,7 \\ -158,7 & -67,7 \\ -9,3 & -2,1 \\ -11,5 & -2,8\end{array}$

6.007

6.007

739

739

0

-

442

442

-

-

39
39
-
-

\begin{tabular}{rrrrrr}
2.789 & 1.777 & 10.214 & 929 & 3.384 & 19.093 \\
2.789 & 1.777 & 10.214 & 929 & 3.384 & 19.093 \\
0 & 0 & 0 & 0 & 0 & 0 \\
- & - & - & - & - & - \\
- & - & - & - & - & - \\
\hline
\end{tabular}

$x^{2}=1001,87854$

Grados de libertad $=32$

Significación $=0,0000$ 
aquellos entrevistados que prefirieron ocultar su Situación Laboral ( «No Contesta»).

Otra forma de analizar la tabla II sería agrupando a los entrevistados en los siguientes grupos de categorías: a) las personas con empleo y, por lo tanto, actualmente en el mercado de trabajo (las cuatro primeras categorias); b) los desempleados que, sin embargo, están en el mercado de trabajo (parados con y sin empleo anterior); c) los que no están en el mercado de trabajo, como los jubilados y pensionistas, los estudiantes y las amas de casa.

En suma, la fuerza de los datos que empleamos no reside en su representatividad, ya que hemos omitido numerosas categorías, sino en el tamaño de la muestra y el detalle con el que se recogieron las respuestas, lo cual nos permite realizar un gran número de tablas de contingencia.

La tab!a IIA recoge el Gi-cuadrado para el conjunto de la tabla, así como los residuos ajustados para cada valor de los cruces. Tal y como esperábamos, el valor del Gi-cuadrado es muy alto (algo mayor que 1.000), siendo muy significativo. De ahí que las frecuencias de las celdillas sean independientes de las frecuencias marginales de filas y columnas.

Incluimos cada uno de los estadísticos necesarios para calcular los residuos ajustados, de manera que el lector cuente con esta información adicional. Recuérdese que los RA se distribuyen aproximadamente de forma normal. Por lo tanto, cualquier valor por encima de 2,6 es significativo al nivel 0,01 . Sin embargo, dado el gran tamaño de la muestra utilizada, emplearemos un patrón más riguroso para determinar cuándo un partido está fuertemente arraigado o es rechazado en una determinada categoría. Usaremos intervalos de tres unidades. Así, si un partido presenta en una categoría un $\mathrm{RA}$ de $+/-3$, interpretaremos que se encuentra significativamente arraigado o que se le rechaza en esa misma medida. Si el valor del RA fuera mayor que 6 , en cualquier sentido, diremos que está fuertemente arraigado o rechazado, dependiendo del signo; y, si ese valor fuera mayor que 9, usaremos la expresión extremadamente arraigado o rechazado.

Siendo ésta la norma general para interpretar los resultados, queremos señalar que, en ocasiones, vamos a desviarnos de esa interpretación. Cuando lo consideremos de interés, también comentaremos aquellos valores de los RA que, siendo superiores a 2,6 y 1,96 , resultan significativos a los niveles del 0,01 y 0,05 , respectivamente.

Vamos a describir y analizar en detalle la tabla IIA, a fin de que el lector se familiarice con el tipo de interpretación aplicada. En adelante, sin embargo, nos concentraremos en los diagramas, mucho menos arduos de leer. La tabla IIA ilustra porqué el lector debería tener en consideración tanto el tamaño absoluto y los porcentajes de las celdillas como sus frecuencias ajustadas. Por ejemplo, en la categoría de trabajadores fijos por cuenta ajena, al $\mathrm{PP}$ se le rechaza fuertemente $(\mathrm{RA}=-7,8)$, mientras que la coalición IU está extremadamente arraigada $(\mathrm{RA}=+9,9)$. Sin embargo, el $\mathrm{PP}$ recibe 
137 votos más que IU en esta categoría de la División del Trabajo. Raíces y recbazos bacen referencia al excedente o déficit obtenido en cada celda, pro. ducto de la diferencia entre los votos esperados y los recibidos, dadas las frecuencias marginales. En cierto sentido, estamos evaluando e interpretando la probabilidad de que se produzca ese excedente o déficit.

Del examen de la primera fila de la tabla IIA (trabajadores por cuenta propia) se desprenden los siguientes resultados: el arraigo del PP es extremo en esa categoría, y significativo, sin llegar a ser fuerte, en lo que respecta al CDS; el PSOE presenta un rechazo extremo, que es sólo significativo en el caso de IU.

Las dos siguientes categorías, asalariados fijos y eventuales, muestran comportamientos similares $y$, en cierto modo, previsibles, aunque también algunas diferencias muy interesantes. En las dos se produce un fuerte rechazo al PP, en tanto que los dos partidos de izquierda reciben un apoyo, cuando menos, significativo. Sin embargo, difieren en lo que respecta a la abstención, al apoyo al CDS y al nivel de apovo a los partidos de izquierda.

Los asalariados eventuales rechazan significativamente al CDS, mientras que en los asalariados fijos no se aprecia ninguna desviación respecto a los marginales esperados. Ambas categorías ofrecen apoyos significativos al PSOE, que son casi fuertes entre los trabajadores fijos. Respecto a IU, los asalariados fijos están, aparentemente, mucho más radicalizados, constituyendo un arraigo extremo para la coalición. A decir verdad, IU tiene su apoyo más contundente y el único extremo en esta categoría. De nuevo, llamamos la atención sobre. las diferencias en los valores absolutos. Entre los asalariados fijos, el PSOE recibe 2.000 votos más que IU.

En la categoría de «Ayuda familiar» no se aprecian desviaciones respecto a los marginales esperados en tres de los cuatro partidos.

A continuación, analizaremos las dos categorías que hacen referencia a los desempleados, ya sean parados que han estado empleados antes o parados que no han encontrado aún su primer empleo; es decir, las dos categorías de entrevistados que, formando parte del mercado de trabajo, se encuentran exciuidas de la población activa. Una vez más, nos encontramos con coincidencias y diferencias. Ambas categorías están sobrerrepresentadas, en lo que respecta a la abstención, a un nivel de significación casi fuerte en los parados previamente empleados y, por encima de ese listón, en los parados sin empleo anterior. La interpretación más obvia es la de que el paro aliena al electorado del proceso político, especialmente a los que nunca han estado empleados. En ambas categorías se aprecia un rechazo al PP, rechazo que es significativo por parte de quienes no han estado empleados antes, y fuerte en lo que respecta a los parados con empleo anterior. Solamente los primeros rechazan al CDS al nivel de significación.

La diferencia más importante atañe al PSOE. Mientras que los parados con empleo anterior muestran su apoyo al PSOE de una forma apenas sig. 
nificativa $(0,05<P<0,01)$, quienes no han estado nunca empleados lo rechazan al nivel de significación. Y esto es así, pese a apreciarse en estos últimos un apoyo significativo a IU, compartido también por la otra categoría de desempleados.

Las coincidencias en los comportamientos de estudiantes y parados sin empleo anterior resultan bastante interesantes. Ambas categorías calan sus raices principales en la abstención, a un nivel extremo en el caso de los estudiantes. En ambas se detecta un apoyo significativo a IU, pero también un rechazo al PSOE, que, de nuevo, es extremo entre los estudiantes. Recuérdese que esta categoría está formada por jóvenes de dieciocho y más años, y que, por lo tanto, es muy probable que cursen estudios universitarios o programas de especialización postsecundarios. En el segundo supuesto provendrían en gran parte del mismo segmento de población que los parados sin empleo anterior, lo que explicaría sus coincidencias en cuanto a las opciones de voto. $\mathrm{Si}$, por el contrario, cursaran en su mayoría estudios universitarios, cabrían dos interpretaciones. La primera apuntaría una tendencia a rechazar al Gobierno y, por lo tanto, al PSOE ${ }^{15}$. Ese rechazo se reflejaría también en la alta proporción de abstenciones y en el apoyo a IU. La explicación alternativa sería la de que los estudiantes se encuentran divididos en dos fracciones distintas, la radical y la de los indiferentes o desentendidos respecto al proceso político. Asumiríamos, de este modo, que la alta sobrerepresentación de la abstención se debe al desinterés, antes que a un rechazo activo del proceso electoral y, en consecuencia, de los partidos políticos. En este punto de la investigación no hay suficientes elementos de juicio que permitan elegir entre una u otra interpretación.

Las dos categorías finales, pensionistas y jubilados, por un lado, y amas de casa, por otro, forman, evidentemente, el segmento de población más numeroso entre los que se encuentran excluidos del mercado de trabajo. En las dos, se aprecia un rechazo significativo de la abstención o, lo que es lo mismo, una participación superior a la que cabría esperar por sus correspondientes frecuencias marginales. Lo más interesante es, sin embargo, el apoyo significativo que las dos categorías conceden, tanto al PSOE como al PP, con una probabilidad que, en el caso de las amas de casa, se sitúa, para el PSOE, entre los niveles de significación del 0,05 y 0,01 . La diferencia está en que pensionistas y jubilados rechazan significativamente al CDS y a IU, mientras que las amas de casa apoyan al CDS al nivel de significación y muestran un rechazo extremo hacia la coalición IU.

El diagrama 1 resume los datos de la tabla IIA.

El eje vertical representa los valores de los residuos ajustados, con dos

15 Aproximadamente en las mismas fechas en que se realizó la encuesta, los estudiantes de enseñanza secundaria sostenían un enfrentamiento con el Gobierno (huelgas, manifestaciones, etc.) sobre cuestiones de su interés, con el apoyo, si no formal, sí real, de gran parte de la población universitaria. 
DIAGRAMA 1

Raices de los partidos en la División del Trabajo en la Sociedad

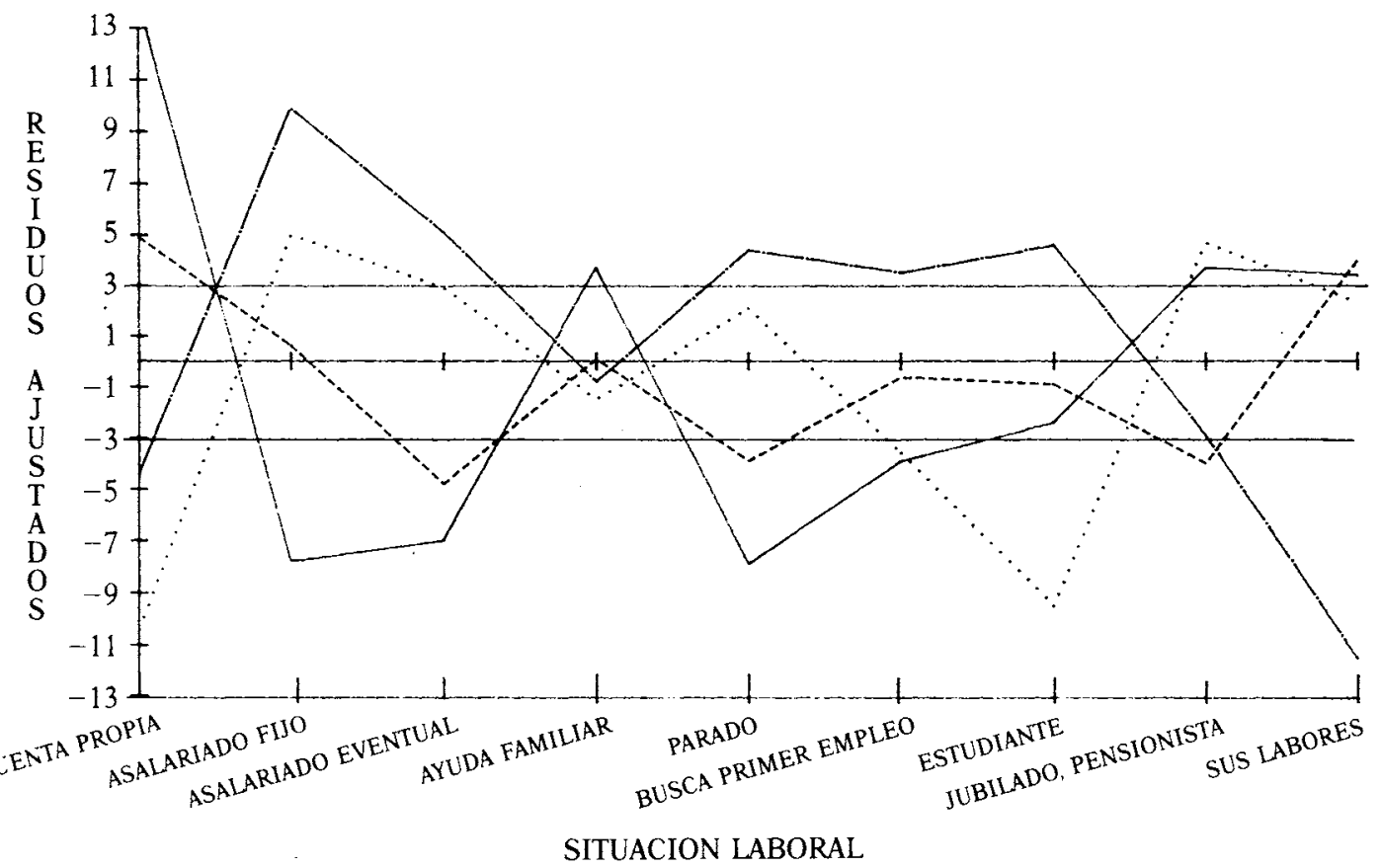

- AP/PDP/PL

- CDS

‥ PSOE

... IU 
líneas que subrayan los niveles positivo y negativo de significación. El eje horizontal recoge las distintas categorías de la División del Trabajo en la Sociedad, mientras que los niveles de apoyo a cada partido se presentan mediante líneas con distinto trazado. De su análisis, extraemos los siguientes resultados: 1) la simetría inversa de apoyos y rechazos, en las tres primeras categorías, entre partidos de izquierda y de derecha; 2) las relativamente pequeñas diferencias entre grupos mostradas por el CDS; 3) la coincidencia entre pensionistas o jubilados y amas de casa respecto a su apoyo a los dos principales partidos, el PSOE y el PP. Por lo tanto, es en estas dos categorías donde la competencia por ampliar el espacio electoral se hace más probable.

En el diagrama 1A se presentan solamente los datos referidos a los dos principales partidos. Cuando las comparaciones se limitan a ellos dos, las diferencias entre quienes están dentro del mercado y quienes están excluidos se hacen más patentes. Otra característica de la División del Trabajo en la Sociedad, en relación al apoyo partidista, es que, entre los asalariados y los parados con empleo anterior, el rechazo al $\mathrm{PP}$ es más fuerte que su aceptación al PSOE. Al menos en lo que respecta a estas categorías, el «techo» electoral del PP se situaría a un nivel bastante bajo, mientras que el «suelo» del PSOE se colocaría en un punto moderadamente alto.

En los diagramas 1B y $1 \mathrm{C}$ se repite el análisis anterior, limitándolo a las tres principales categorías de población activa (los datos se presentan en las tablas IIB y IIC).

Cuando se comparan los cuatro partidos, la línea del CDS vuelve a estar situada dentro de los márgenes delimitados por los otros partidos, es decir, presenta los valores relativamente menos significativos de RA. Un cambio que afecta a esta subtabla es que el PSOE recibe un apoyo algo mayor que IU en las dos clases de trabajadores asalariados. Finalmente, una vez más el nivel de rechazo al PP entre los trabajadores asalariados es mucho mayor que el nivel de apoyo al PSOE, que pasa a ser fuerte entre los empleados fijos y significativo entre los eventuales. El diagrama $1 \mathrm{C}$, donde esa información se limita a los dos partidos, refuerza esta interpretación.

En suma, del análisis de las categorías de la División del Trabajo en la Sociedad se desprende que el CDS está débilmente arraigado; que, entre los trabajadores con empleo, el PP sólo disfruta de un arraigo extremo entre los que trabajan por cuenta propia, mientras que recibe el mayor rechazo de los asalariados, con una intensidad que va de fuerte a extrema. Por último, habría que señalar que es precisamente entre las categorías que no forman parte del mercado de trabajo donde los partidos se muestran más competitivos. Nótese, sin embargo, que las amas de casa forman la categoría con mayor número de casos. 
DIAGRAMA $1 \mathrm{~A}$

Raices de los partidos en la División del Trabajo en la Sociedad
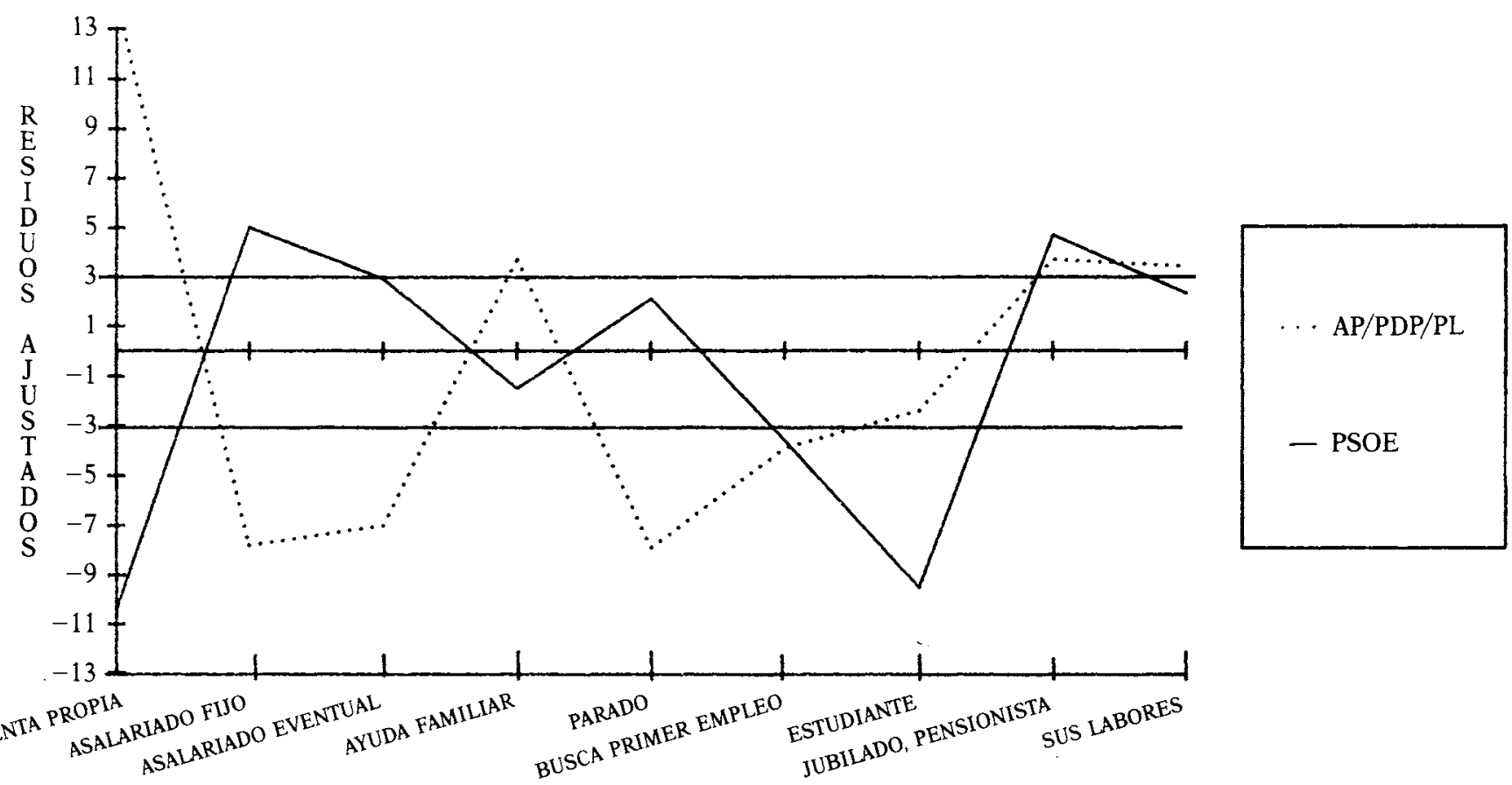

SITUACION LABORAL 
Raices de los partidos en la División del Trabajo en la Sociedad

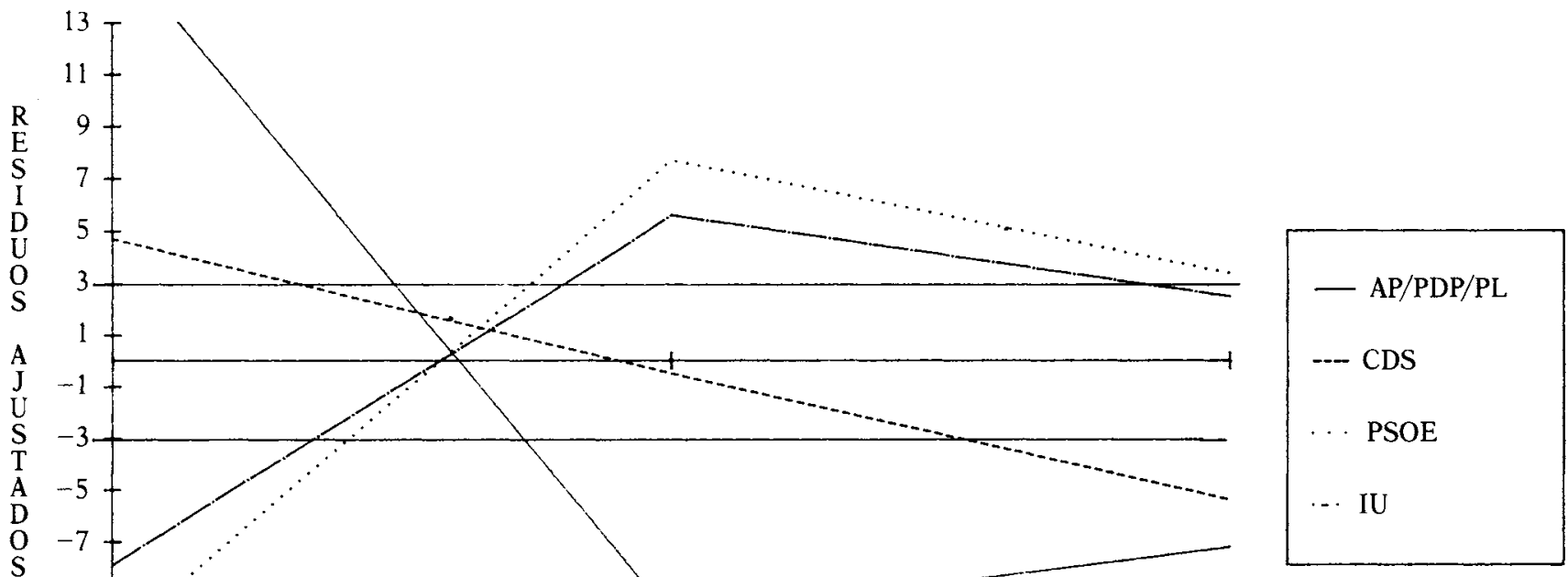

CUENTA PROPIA

ASALARIADO FIJO

SITUACION LABORAL

POBLACION ACTIVA (EXCLUIDA AYUDA FAMILIAR) 


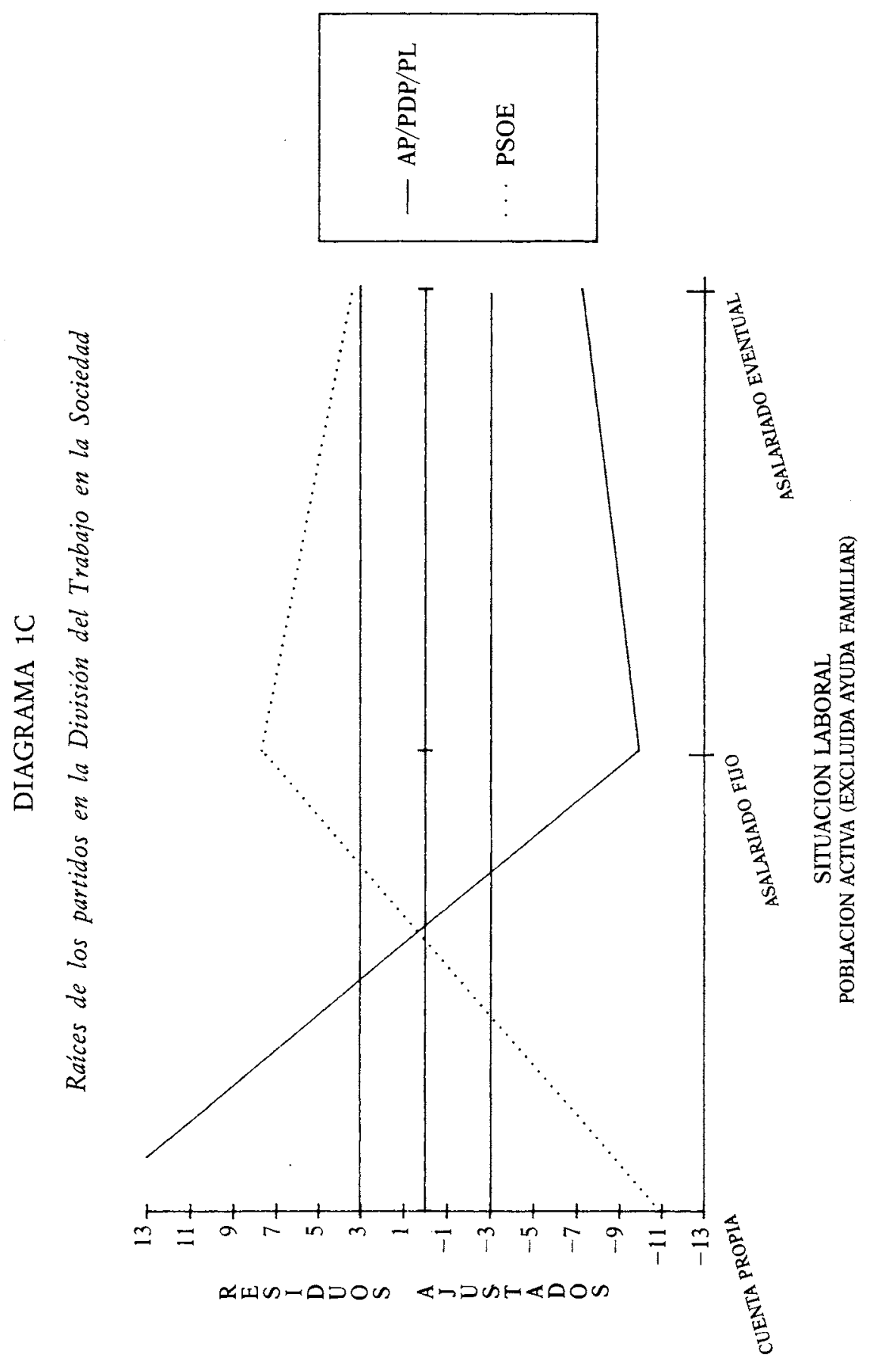




\section{TABLA IIB}

\section{RECUERDO VOTO GENERALES DEL 86}

\section{Situación laboral}

(pablación activa)

Trabaja por cuenta propia

\begin{tabular}{|c|c|c|c|c|c|c|}
\hline Absolutos ... & 585 & 292 & 1.065 & 75 & 418 & 2.435 \\
\hline$\%$ columna $\ldots \ldots$ & 51,3 & 38,3 & 25,5 & 15,1 & 31,9 & 30,9 \\
\hline$\%$ Fila & 24,0 & 12,0 & 43,7 & 3,1 & 17,2 & 100,0 \\
\hline$\%$ tabla $\ldots$ & 7,4 & 3,7 & 13,5 & 1,0 & 5,3 & 30,9 \\
\hline
\end{tabular}

Asalariado fijo

\begin{tabular}{|c|c|c|c|c|c|c|}
\hline Absolutos & 469 & 410 & 2.443 & 332 & 643 & 4.298 \\
\hline$\%$ columna & 41,1 & 53,7 & 58,6 & 66,5 & 49,1 & 54,5 \\
\hline$\%$ fila & 10,9 & 9,5 & 56,8 & 7,7 & 15,0 & 100,0 \\
\hline$\%$ tabla & 6,0 & 5,2 & 31,0 & 4,2 & 8,2 & 54,5 \\
\hline
\end{tabular}

Asalariado eventual

$\begin{array}{lllllrrrrrr}\text { Absolutos } \ldots & \ldots & \ldots & \ldots & & 87 & 61 & 662 & 92 & 248 & 1.150 \\ \% \text { columna } & \ldots & \ldots & \ldots & 7,6 & 8,0 & 15,9 & 18,4 & 18,9 & 14,6 \\ \% \text { fila } \ldots & \ldots & \ldots & \ldots & \ldots & 7,6 & 5,3 & 57,6 & 8,0 & 21,6 & 100,0 \\ \% \text { tabla } \ldots & \ldots & \ldots & \ldots & \ldots & 1,1 & 0,8 & 8,4 & 1,2 & 3,1 & 14,6\end{array}$

Total

\begin{tabular}{|c|c|c|c|c|c|c|}
\hline Absolutos $\ldots . . . \quad \ldots .$. & 1.142 & 763 & 4.170 & 499 & 1.309 & 7.883 \\
\hline$\%$ columna $\ldots \begin{array}{lll} & \ldots & \ldots\end{array}$ & 100,0 & 100,0 & 100,0 & 100,0 & 100,0 & 100,0 \\
\hline$\%$ fila $\ldots \ldots \ldots \ldots$ & 14,5 & 9,7 & 52,9 & 6,3 & 16,6 & 100,0 \\
\hline$\%$ tabla $\ldots . .$. & 14,5 & 9,7 & 52,9 & 6,3 & 16,6 & 100,0 \\
\hline
\end{tabular}




\section{TABLA IIC}

\section{Situación laboral}

(población activa)

Trabaja por cuenta propia

Absolutos . . . . . . . . . .

Frecuencia esperada ...

Residuos ... ... ... ...

Residuos estandarizados

Residuos ajustados ....

Asalariado fijo

Absolutos ............

Frecuencia esperada ...

Residuos ... ... ... ...

Residuos estandarizados

Resiciuos ajustados . ...

Asalariado eventual

Absolutos ...........

Frecuencia esperada ...

$\begin{array}{llll}\text { Residuos } & \ldots & \ldots & \ldots\end{array}$

Residuos ajustados ....

Total

Absolutos ... $\ldots . \ldots \ldots$

Frecuencia esperada ...

Residuos $\ldots \ldots \ldots \ldots$

Residuos estandarizados

Residuos ajustados . ...

$x^{2}=404,88212$

\section{RECUERDO VOTO GENERALES DEL 86}

\begin{tabular}{|c|c|c|c|c|}
\hline $\begin{array}{c}A P-P D P . \\
P L\end{array}$ & $C D S$ & PSOE & $I U$ & $\begin{array}{l}\text { Absten- } \\
\text { cionistas }\end{array}$ \\
\hline
\end{tabular}

$\begin{array}{rrrrrr}585 & 292 & 1.065 & 75 & 418 & 2.435 \\ 352,7 & 235,6 & 1.288,2 & 154,3 & 404,4 & 2.435 \\ 232,8 & 56,5 & -223,6 & -79,0 & 13,3 & 0 \\ 12,4 & 3,7 & -6,2 & -6,4 & 0,7 & - \\ 16,1 & 4,7 & -10,9 & -7,9 & 0,9 & -\end{array}$

$\begin{array}{rrrrrr}469 & 410 & 2.443 & 332 & 643 & 4.298 \\ 622,4 & 415,8 & 2.273,4 & 272,2 & 713,8 & 4.298 \\ -153,3 & -6,2 & 169,8 & 60,1 & -70,3 & 0 \\ -6,1 & -0,3 & 3,6 & 3,6 & -2,6 & - \\ -9,9 & -0,5 & 7,7 & 5,6 & -4,3 & -\end{array}$

$\begin{array}{rrrrrr}87 & 61 & 662 & 92 & 248 & 1.150 \\ 166,6 & 113,3 & 608,5 & 72,9 & 191,1 & 1.150 \\ -79,5 & -50,3 & 53,9 & 18,9 & 57,0 & 0 \\ -6,2 & -4,8 & 2,2 & 2,2 & 4,1 & - \\ -7,2 & -5,4 & 3,4 & 2,5 & 4,9 & -\end{array}$

$\begin{array}{rrrrrr}1.142 & 763 & 4.170 & 499 & 1.309 & 7.883 \\ 1.142 & 763 & 4.170 & 499 & 1.309 & 7.883 \\ 0 & 0 & 0 & 0 & 0 & 0 \\ - & - & - & - & - & - \\ - & - & - & - & - & -\end{array}$

Grados de libertad $=8$

Significación $=0,0000$ 


\section{La División Industrial del Trabajo}

Tal y como discutimos antes, la posición en el mercado se mide mediante la variable Ocupación. Limitaremos nuestro análisis de las relaciones entre la posición en el mercado y el apoyo partidista a los entrevistados que están actualmente empleados. Con esta limitación, el tamaño de la muestra utilizada se reduce considerablemente, de 19.093 a 7.738 casos. La diferencia radica, evidentemente, en la supresión de las categorías de desempleados, pensionistas y jubilados, amas de casa y estudiantes de la tabla II. No obstante, el tamaño del $\mathrm{N}$ permanece suficientemente grande como para permitirnos realizar el análisis previsto, así como para analizar algunas subtablas de interés. En consecuencia, aún podremos analizar esta variable con un considerable detalle.

Empezaremos por las ocho categorías ocupacionales más importantes. El gráfico 2 provee una imagen clara del tamaño relativo de cada una de estas categorías para el segmento de población activa extraído del conjunto de la muestra. El cruce entre Ocupación y Recuerdo de Voto se presenta en las tablas III y IIIA. Como antes, la primera recoge los absolutos y porcentajes y, la segunda, los residuos ajustados y los estadísticos que permiten calcularlos.

Nótese que para este análisis de la posición dentro del mercado omitimos la categoría formada por los trabajadores empleados en concepto de Ayuda Familiar. No sólo porque constituyen un segmento pequeño en comparación con las otras categorías, sino, sobre todo, porque su estatus ocupacional resuita poco claro. Por ejemplo, algunos de ellos sólo trabajan a tiempo parcial y realizan un gran número de tareas distintas.

Para empezar con las abstenciones, es decir, con la última columna, interesa resaltar que la categoría de los profesionales está extremadamente sobrerepresentada. Al menos en lo que respecta a los cuatro partidos nacionales, parcce que ninguno de ellos satisface suficientemente a los profesionales. Rechazan fuertemente al PSOE, pero no extienden sus raíces a ninguno de los otros tres partidos. En cuanto al comportamiento de los Administradores de nivel inferior, apenas sí se abstienen de votar por encima de lo que cabría esperar por su tamaño relativo, ya que alcanzan una significación al nivel del 0,05 . Los pequeños propietarios agrícolas, los trabajadores cualificados y los semicualificados se alejan significativamente de la abstención, mostrando los últimos una fuerte tendencia hacia la participación.

En nuestro análisis de las relaciones entre la posición en el mercado, u ocupación, y el apoyo partidista, alteraremos el modo de presentación. Nos apoyaremos más en los diagramas, utilizando la tabla IIIA para presentar el tamaño de los residuos ajustados.

El diagrama 2 muestra la repetida ausencia de arraigo del CDS en el segmento de población activa de la muestra. Lo único que merece comentarse 
es el rechazo significativo que ese partido recibe por parte de los trabajadores no cualificados. En relación a IU, la coalición se ve significativamente rechazada por los administradores de nivel medio, por los pequeños propietarios agrícolas y por los artesanos. La coalición sólo tiene un arraigo significativo entre los trabajadores semicualificados, aunque mucho más débil que el del PSOE. Por lo tanto, los resultados más importantes de la relación entre la ocupación y el apoyo electoral están limitados a los dos partidos principa. les (diagrama 2A).

Los resultados referidos al grupo de Profesionales, Semiprofesionales y Técnicos son mucho más interesantes. Se aprecia un fuerte rechazo al PSOE, pero ningún apoyo al PP. Volviendo a la tabla IIIA, parecería como si los profesionales prefirieran abstenerse antes que votar al PP (o al CDS). Se advierte una simetría inversa entre los dos partidos principales en relación a los Propietarios, Directivos y Administradores de nivel medio, y respecto a los Pequeños Propietarios Agrícolas. En ambas categorías se apoya extremadamente al PP y se rechaza fuertemente al PSOE. Los Administradores de nivel inferior rechazan al PSOE al nivel de significación del 0,05 , pero no muestran ningún apoyo al PP. Esta tendencia se mantiene en los Artesanos, manifestándose en un cierto apoyo al PP y en neutralidad ante el PSOE. Es precisamente en estas dos últimas categorías donde los dos partidos podrían competir.

En las tres últimas categorías, es decir, en los Trabajadores Cualificados, Semicualificados y No Cualificados, se repite la tendencia a la simetría inversa. En las dos primeras se observa un fuerte rechazo al PP y un fuerte arraigo del PSOE. En la última, es decir, en los Trabajadores No Cualificados, se sigue apreciando un rechazo fuerte al PP, pero el apoyo al PSOE cae a un nivel entre significativo y fuerte.

Volviendo al gráfico 2, podemos ver cómo el apoyo al PP proviene de un conjunto de categorías que representan el 23,6 por 100 de la muestra utilizada, porcentaje que sube al 53,2 por 100 cuando se toman en consideración los grupos ocupacionales que apoyan al PSOE. Este es otro aspecto más del «techo» del PP al que aludíamos en el análisis de la División del Trabajo en la Sociedad, que se manifiesta en el pequeño tamaño de las categorías de la DIT donde el PP extiende sus raíces más profundas. 
Ocupación. Población activa (excluida Ayuda Familiar)

(Distribución porcentual)

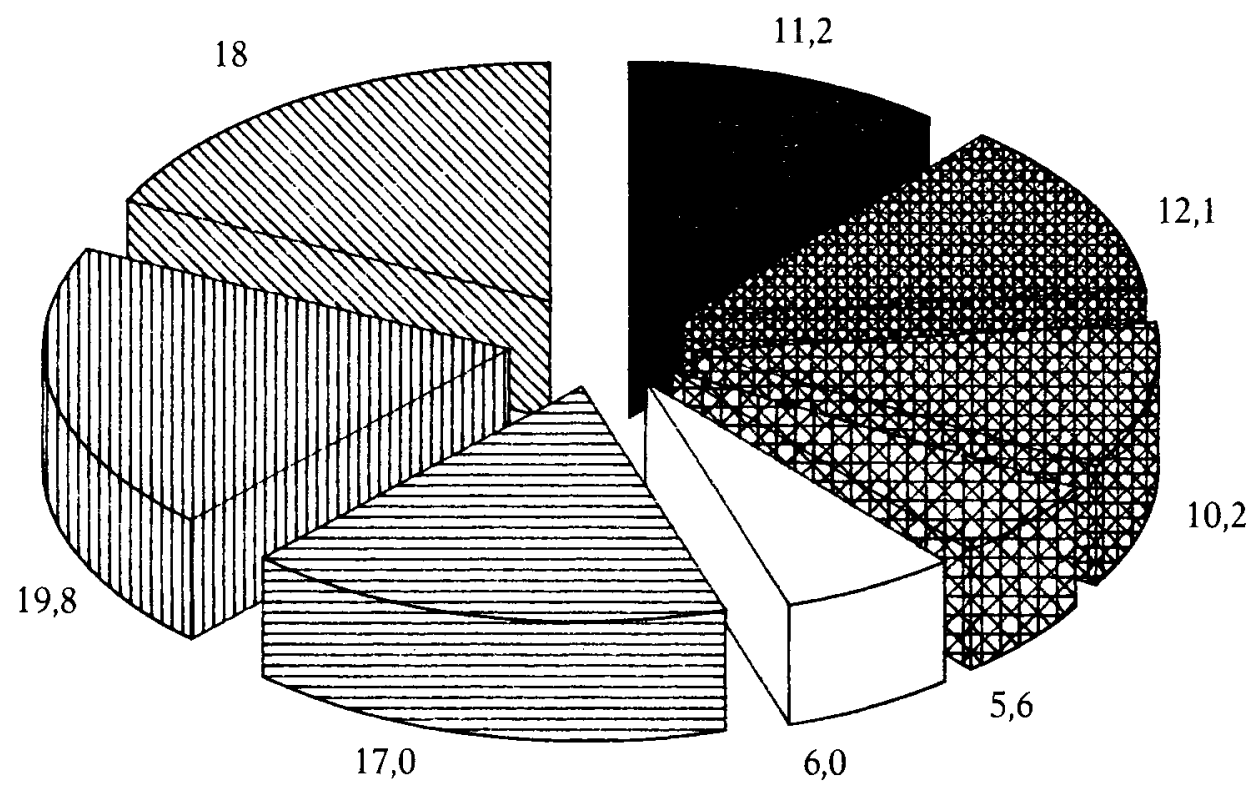

$\mathrm{N}=7.738$

PROFES. Y TECNICOS

DIREC./ ADMINISTRADOR

PROPIETARIOS AGRICOLAS

ADMI. NIVEL INFERIOR

ARTESANOS

CUALIFICADOS

IIII SEMICUALIF.

N NO CUALIF. 


\section{TABLA III}

\section{RECUERDO VOTO GENERALES DEL 86}

\begin{tabular}{|c|c|c|c|c|c|}
\hline $\begin{array}{c}A P \cdot P D P- \\
\quad P L\end{array}$ & $C D S$ & PSOE & $I U$ & $\begin{array}{c}\text { Absten- } \\
\text { cionistas }\end{array}$ & Total \\
\hline 125 & 82 & 357 & 62 & 240 & 867 \\
\hline 11,2 & 11,0 & 8,7 & 12,7 & 18,6 & 11,2 \\
\hline 14,4 & 9,5 & 41,2 & 7,2 & 27,7 & 100,0 \\
\hline 1,6 & 1,1 & 4,6 & 0,8 & 3,1 & 11,2 \\
\hline
\end{tabular}

Propietarios, directivos y administradores (nivel medio)

Absolutos .............

$\%$ columna $\ldots \ldots+\ldots$

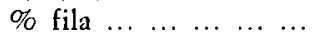

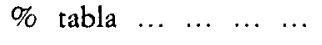

23199

$20,7 \quad 13,0$

$24,8 \quad 10,5$

$3,0 \quad 1,3$

132

11,8

16,8

$\begin{array}{llllllr}\% & \text { tabla } & \ldots & \ldots & \ldots & \ldots & \ldots\end{array}$

\section{Artesanos}

Absolutos ... $\ldots \ldots \ldots$

$\%$ columna $\ldots \ldots \ldots$

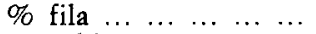

$\%$ tabla $\ldots \begin{array}{llll}\% & \ldots & \ldots & \ldots\end{array}$

Pequeños propietarios

$$
\text { agrícolas }
$$

Absolutos ... ... ......

$\%$ columna $\ldots$...

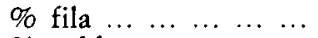

$\%$ tabla $\ldots \begin{array}{llll}\% & \ldots & \ldots & \ldots\end{array}$

Supervisores, capataces y trabajadores cualificados

Absolutos ... $\ldots . . . . .$.

$\begin{array}{lllll}\% & \text { columna } & \ldots & \ldots & \ldots\end{array}$

$\%$ fila $\ldots \begin{array}{lllll} & \ldots & \ldots & \ldots & \ldots\end{array}$

$\%$ tabla $\ldots \begin{array}{llll}\% & \ldots & \ldots & \ldots\end{array}$
170

15,2

36,3

2,2

58
7,8
12,5

12,5
0,8

120

10,8

9,1

1,6

117

15,6

8,8

1,5

83
11,1
10,5
1,1

53

7,1

12,1

0,7
408

10,0

43,7

5,3

381

9,3

48,2

4,9

230

5,6

52,7

3,0

174

4,3

37,3

2,3
800

19,6

60,7

10,3

\section{1}

8,3

5,2

0,5

13

2,6

3,0

0,2

Trabajadores semicualificados

Ảbsolutos $\ldots . . . . . . . .$.

$\begin{array}{lllll}\% & \text { columna } & \ldots & \ldots & \ldots\end{array}$

$\%$ fila $\ldots \ldots \ldots c c c c$ 
TABLA III (Continuación)

\begin{tabular}{|c|c|c|c|c|c|c|}
\hline & \multicolumn{5}{|c|}{ RECUERDO VOTO GENERALES DEL 86} & \multirow[b]{2}{*}{ Total } \\
\hline & $\begin{array}{l}A P-P D P- \\
\quad P L\end{array}$ & $C D S$ & PSOE & IU & $\begin{array}{l}\text { Absten- } \\
\text { cionistas }\end{array}$ & \\
\hline \multicolumn{7}{|l|}{$\begin{array}{l}\text { Trabajadores no cualifica- } \\
\text { dos }\end{array}$} \\
\hline Absolutos $\ldots \ldots \ldots \ldots$ & 122 & 101 & 815 & 108 & 245 & 1.392 \\
\hline$\%$ columna $\ldots \ldots \ldots$ & 10,9 & 13,5 & 19,9 & 22,1 & 19,0 & 18,0 \\
\hline$\%$ fila $\ldots \ldots \ldots c c c c$ & 8,7 & 7,3 & 58,6 & 7,8 & 17,6 & 100,0 \\
\hline$\%$ tabla $\ldots \begin{array}{llll} & \ldots & \ldots & \ldots\end{array}$ & 1,6 & 1,3 & 10,5 & 1,4 & 3,2 & 18,0 \\
\hline \multicolumn{7}{|l|}{ Total } \\
\hline Absolutos $\ldots \ldots \ldots \ldots$ & 1.118 & 750 & 4.090 & 491 & 1.288 & 7.738 \\
\hline$\%$ columna $\ldots \ldots \ldots$ & 100,0 & 100,0 & 100,0 & 100,0 & 100,0 & 100,0 \\
\hline$\%$ fila $\ldots \ldots \ldots \ldots \ldots$ & 14,5 & 9,7 & 52,9 & 6,3 & 16,7 & 100,0 \\
\hline $\begin{array}{llllll}\% & \text { tabla } & \ldots & \ldots & \ldots & \ldots\end{array}$ & 14,5 & 9,7 & 52,9 & 6,3 & 16,7 & 100,0 \\
\hline
\end{tabular}

TABLA IIIA

\begin{tabular}{|c|c|c|c|c|c|c|}
\hline & \multicolumn{5}{|c|}{ RECUERDO VOTO GENERALES DEL 86} & \multirow[b]{2}{*}{ Total } \\
\hline & $\begin{array}{l}A P-P D P- \\
\quad P L\end{array}$ & $C D S$ & PSOE & $I U$ & $\begin{array}{l}\text { Absten- } \\
\text { cionistas }\end{array}$ & \\
\hline \multicolumn{7}{|l|}{ Ocupación } \\
\hline \multicolumn{7}{|l|}{$\begin{array}{l}\text { Profesionales, semiprofe- } \\
\text { sionales y técnicos }\end{array}$} \\
\hline 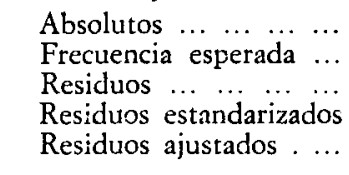 & $\begin{array}{r}125 \\
125,3 \\
-0,1 \\
-0,0 \\
-0,0\end{array}$ & $\begin{array}{r}82 \\
84,0 \\
-1,7 \\
-0,2 \\
-0,2\end{array}$ & $\begin{array}{r}357 \\
458,1 \\
-101,1 \\
-4,7 \\
-7,3\end{array}$ & $\begin{array}{r}62 \\
55,0 \\
7,2 \\
1,0 \\
1,1\end{array}$ & $\begin{array}{r}240 \\
144,3 \\
95,7 \\
8,0 \\
9,3\end{array}$ & $\begin{array}{r}867 \\
867 \\
0 \\
- \\
-\end{array}$ \\
\hline \multicolumn{7}{|l|}{$\begin{array}{l}\text { Propietarios, directivos y } \\
\text { administradores (nivel } \\
\text { medio) }\end{array}$} \\
\hline $\begin{array}{lllll}\text { Absolutos } & \ldots & \ldots & \ldots & \ldots \\
\text { Frecuencia } & \text { esperada } & \ldots \\
\text { Residuos } \ldots & \ldots & \ldots & \ldots \\
\text { Residuos estandarizados } \\
\text { Residuos ajustados } \ldots\end{array}$ & $\begin{array}{r}231 \\
134,9 \\
96,1 \\
8,3 \\
9,5\end{array}$ & $\begin{array}{r}98 \\
90,5 \\
7,2 \\
0,8 \\
0,8\end{array}$ & $\begin{array}{r}408 \\
493,3 \\
-85,5 \\
-3,8 \\
-6,0\end{array}$ & $\begin{array}{r}32 \\
59,3 \\
-27,5 \\
-3,6 \\
-3,9\end{array}$ & $\begin{array}{r}165 \\
155,4 \\
9,6 \\
0,8 \\
0,9\end{array}$ & $\begin{array}{r}933 \\
933 \\
0 \\
- \\
-\end{array}$ \\
\hline \multicolumn{7}{|l|}{$\begin{array}{l}\text { Administradores (nivel in- } \\
\text { ferior) }\end{array}$} \\
\hline 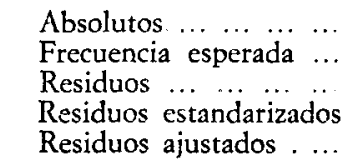 & $\begin{array}{r}132 \\
114,1 \\
18,2 \\
1,7 \\
1,9\end{array}$ & $\begin{array}{r}83 \\
76,6 \\
6,7 \\
0,8 \\
0,9\end{array}$ & $\begin{array}{r}381 \\
417,4 \\
-36,4 \\
-1,8 \\
-2,7\end{array}$ & $\begin{array}{r}41 \\
50,1 \\
-9,3 \\
-1,3 \\
-1,4\end{array}$ & $\begin{array}{r}152 \\
131,5 \\
20,9 \\
1,8 \\
2,1\end{array}$ & $\begin{array}{r}790 \\
790 \\
0 \\
- \\
-\end{array}$ \\
\hline
\end{tabular}


TABLA IIIA (Continuación)

\begin{tabular}{|c|c|c|c|c|c|c|}
\hline & \multicolumn{5}{|c|}{ RECUERDO VOTO GENERALES DEL 86} & \multirow[b]{2}{*}{ Total } \\
\hline & $\begin{array}{l}A P-P D P- \\
P L\end{array}$ & $C D S$ & PSOE & $I U$ & $\begin{array}{l}\text { Absten- } \\
\text { cionistas }\end{array}$ & \\
\hline \multicolumn{7}{|l|}{ Artesanos } \\
\hline 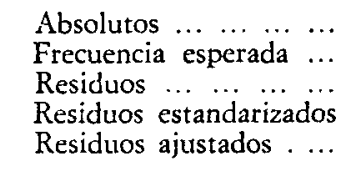 & $\begin{array}{r}82 \\
63,0 \\
19,2 \\
2,7 \\
2,7\end{array}$ & $\begin{array}{r}53 \\
42,3 \\
10,7 \\
1,6 \\
1,8\end{array}$ & $\begin{array}{r}230 \\
230,5 \\
-0,6 \\
-0,0 \\
-0,1\end{array}$ & $\begin{array}{r}13 \\
27,7 \\
-14,7 \\
-2,8 \\
-3,0\end{array}$ & $\begin{array}{r}58 \\
72,6 \\
-14,5 \\
-1,7 \\
-1,9\end{array}$ & $\begin{array}{r}436 \\
436 \\
0 \\
- \\
-\end{array}$ \\
\hline \multicolumn{7}{|l|}{$\begin{array}{l}\text { Pequeños propietarios } \\
\text { agrícolas }\end{array}$} \\
\hline 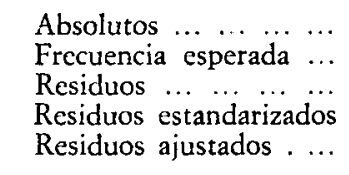 & $\begin{array}{r}170 \\
67,5 \\
102,1 \\
12,4 \\
13,9\end{array}$ & $\begin{array}{r}58 \\
45,3 \\
13,1 \\
1,9 \\
2,1\end{array}$ & $\begin{array}{r}174 \\
246,8 \\
-72,6 \\
-4,6 \\
-6,9\end{array}$ & $\begin{array}{r}9 \\
29,7 \\
-21,0 \\
-3,9 \\
-4,1\end{array}$ & $\begin{array}{r}56 \\
77,8 \\
-21,7 \\
-2,5 \\
-2,8\end{array}$ & $\begin{array}{r}467 \\
467 \\
0 \\
- \\
-\end{array}$ \\
\hline \multicolumn{7}{|l|}{$\begin{array}{l}\text { Supervisores, capataces y } \\
\text { trabajadores cualificados }\end{array}$} \\
\hline 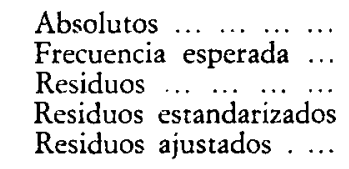 & $\begin{array}{r}120 \\
190,5 \\
-70,3 \\
-5,1 \\
-6,0\end{array}$ & $\begin{array}{r}117 \\
127,8 \\
-11,1 \\
-1,0 \\
-1,1\end{array}$ & $\begin{array}{r}800 \\
696,7 \\
103,2 \\
3,9 \\
6,3\end{array}$ & $\begin{array}{r}100 \\
83,7 \\
15,8 \\
1,7 \\
2,0\end{array}$ & $\begin{array}{r}182 \\
219,5 \\
-37,7 \\
-2,5 \\
-3,1\end{array}$ & $\begin{array}{r}1.318 \\
1.318 \\
0 \\
- \\
-\end{array}$ \\
\hline \multicolumn{7}{|l|}{$\begin{array}{l}\text { Trabajadores semicualifi- } \\
\text { cados }\end{array}$} \\
\hline 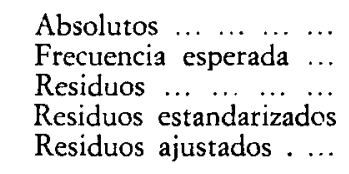 & $\begin{array}{r}136 \\
221,8 \\
-85,7 \\
-5,8 \\
-6,9\end{array}$ & $\begin{array}{r}158 \\
148,8 \\
8,8 \\
0,7 \\
0,8\end{array}$ & $\begin{array}{r}925 \\
811,3 \\
113,2 \\
4,0 \\
6,5\end{array}$ & $\begin{array}{r}127 \\
97,5 \\
29,4 \\
3,0 \\
3,4\end{array}$ & $\begin{array}{r}190 \\
255,6 \\
-65,7 \\
-4,1 \\
-5,0\end{array}$ & $\begin{array}{r}1.535 \\
1.535 \\
0 \\
- \\
-\end{array}$ \\
\hline \multicolumn{7}{|l|}{$\begin{array}{l}\text { Trabajadores no cualifica. } \\
\text { dos }\end{array}$} \\
\hline 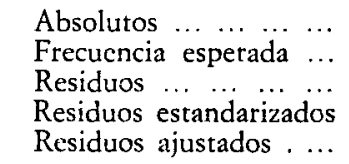 & $\begin{array}{r}122 \\
201,1 \\
-79,6 \\
-5,6 \\
-6,7\end{array}$ & $\begin{array}{r}101 \\
134,9 \\
-33,6 \\
-2,9 \\
-3,4\end{array}$ & $\begin{array}{r}815 \\
735,6 \\
79,8 \\
2,9 \\
4,7\end{array}$ & $\begin{array}{r}108 \\
88,4 \\
20,1 \\
2,1 \\
2,4\end{array}$ & $\begin{array}{r}245 \\
231,7 \\
13,4 \\
0,9 \\
1,1\end{array}$ & $\begin{array}{r}1.392 \\
1.392 \\
0 \\
- \\
-\end{array}$ \\
\hline \multicolumn{7}{|l|}{ Total } \\
\hline 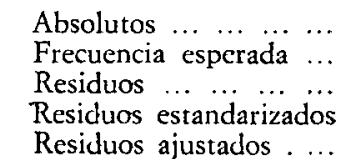 & $\begin{array}{r}1.118 \\
1.118 \\
0 \\
-\end{array}$ & $\begin{array}{r}750 \\
750 \\
0 \\
- \\
-\end{array}$ & $\begin{array}{r}4.090 \\
4.090 \\
0 \\
-\end{array}$ & $\begin{array}{r}491 \\
491 \\
0 \\
-\end{array}$ & $\begin{array}{r}1.288 \\
1.288 \\
0 \\
-\end{array}$ & $\begin{array}{r}7.738 \\
7.738 \\
0 \\
-\end{array}$ \\
\hline
\end{tabular}




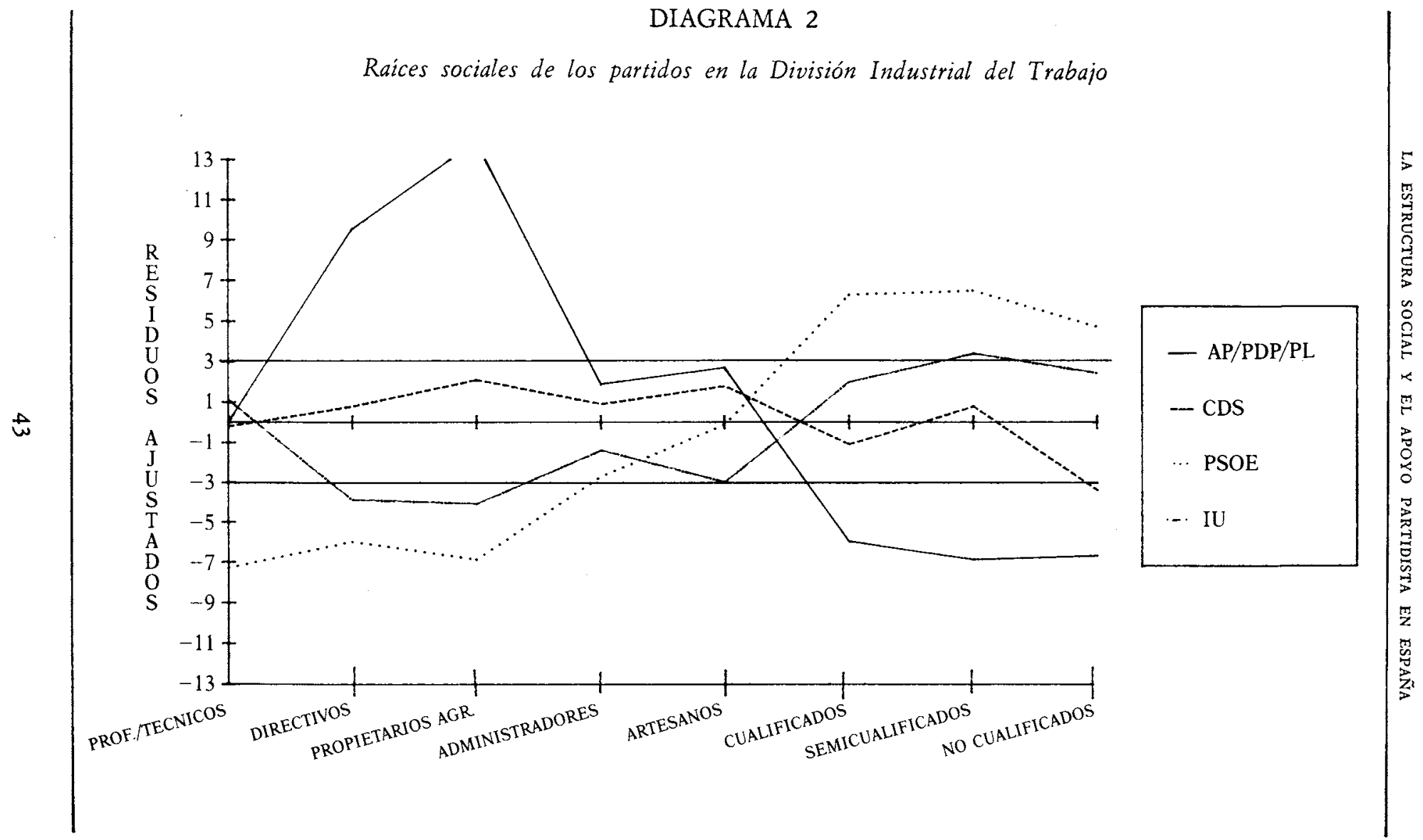




\section{DIAGRAMA 2A}

Raices sociales de los partidos en la División Industrial del Trabajo

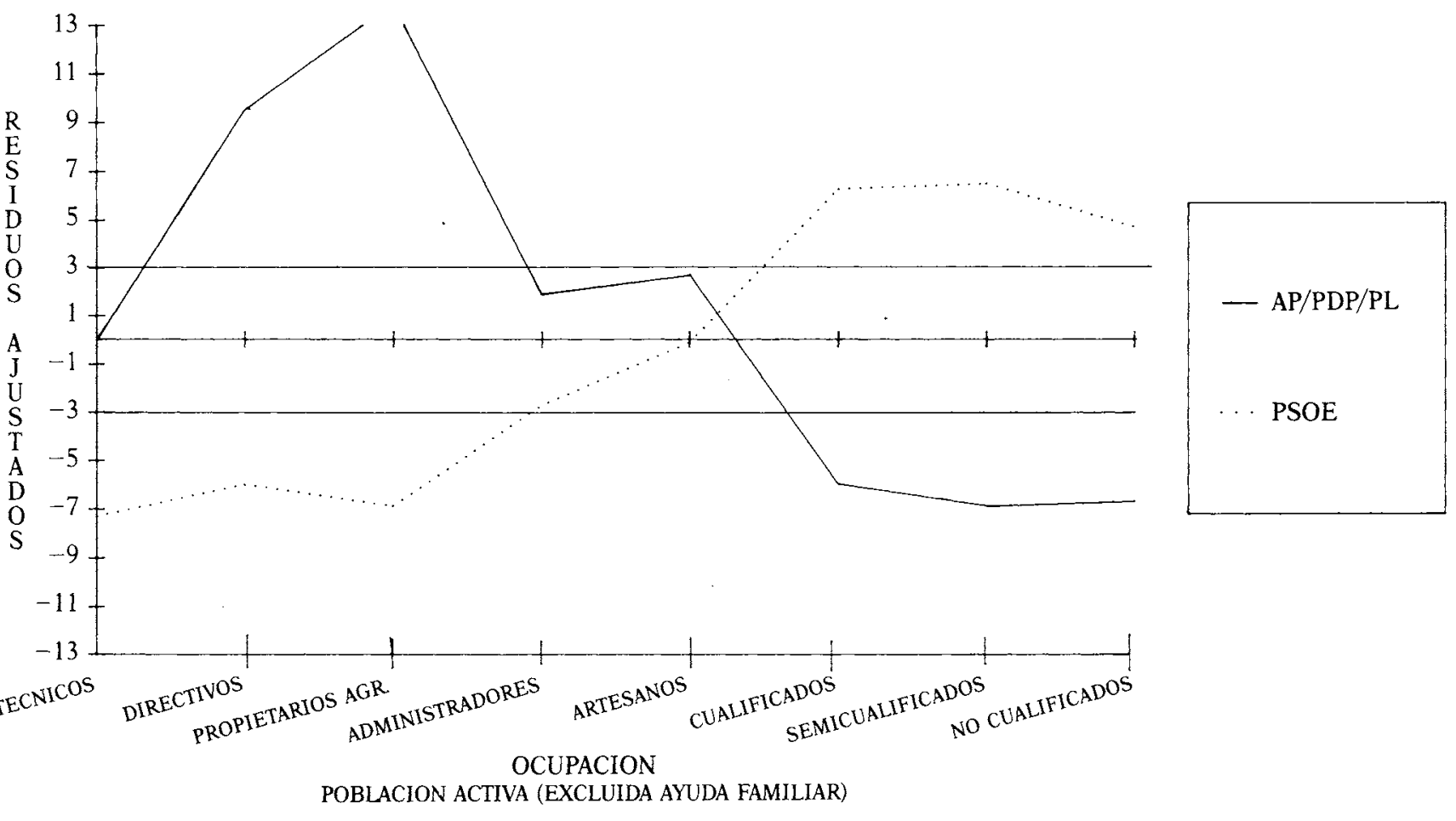




\section{Análisis detallado de la Ocupación y el Apoyo Partidista}

Estos resultados nos llevaron a examinar las categorías ocupacionales con un mayor nivel de detalle (véase la sección sobre las variables independientes). Sin embargo, este mayor grado de especificación altera el significado de los estadísticos. Lo que presentamos a continuación es el análisis de cada categoria ocupacional, en lugar del análisis precedente entre categorias ocupacionales. Dado el gran tamaño del $\mathrm{N}$ y de los RA obtenidos en el análisis entre categorías ocupacionales, y el intento deliberado que entonces se hizo de obtener homogeneidad dentro de las principales categorías, cabe suponer que, en el actual análisis intra-categorías, tanto el Gi-cuadrado global para las subtablas, como los RA, serán mucho más pequeños. En algunos casos. incluso podrían aparecer resultados contradictorios. Lo que intentamos explicar es que, cuando limitamos el análisis a una categoría ocupacional, algunas subcategorías pueden constituir, en comparación con otras, raíces para un determinado partido, aunque éste sea rechazado en esa ocupación, considerada globalmente. Dicho de otro modo, la ausencia de efectos significativos en las subcategorías de cada ocupación no modifica en absoluto los resultados para los análisis entre ocupaciones.

Las tablas IIIB y IIIC presentan los resultados para las tres subcategorías incluidas en la categoría principal de Profesionales, Semiprofesionales y Técnicos.

Aunque el Gi-cuadrado total para estas subtablas no alcanza el nivel de significación del 0,05 , lo hemos incluido aquí porque revela un hallazgo interesante. Recuérdese que en los diagramas 2 y $2 \mathrm{~A}$, los Profesionales rechazaban al PSOE, pero no apoyaban de ningún modo al PP. En aquel momento interpretábamos que, para este grupo, la abstención resultaba una opción más atractiva que votar al PP.

La tabla IIIC, en parte extiende y modifica esta interpretación. Permite una especificación de ese resultado en las tres subcategorías, claramente diferentes entre sí. En los Profesionales Tradicionales, el PP muestra un arraigo débil, pero significativo al nivel del 0,05 . Los Técnicos siguen siendo neutrales respecto a su opción electoral. Sin embargo, los Semiprofesionales muestran un rechazo significativo hacia el PP al nivel del 0,01 . Debido a que estos últimos constituyen la fracción más pequeña de la categoría global, su rechazo se contrarresta por la posición débil y neutral de las otras dos subcategorías más grandes.

Propietarios y Administradores. Los Propietarios y los Administradores se descomponen ahora en tres categorías principales, aunque en las tablas anteriores (tabla IIIA y diagramas 2 y $2 \mathrm{~A}$ ) sólo figuraran dos: la de los Propietarios, Directivos y Administradores de nivel medio, por un lado, y la de 
TABLA IIIB

Profesionales, semi-

profesionales y técnicos

Científicos, ingenieros $y$ otras profesiones tradicionales

Absolutos .............

$\%$ columna $\ldots \ldots$...

$\%$ fila $\ldots \ldots \ldots c c c c$

$\begin{array}{llllll}\% & \text { tabla } & \ldots & \ldots & \ldots & \ldots\end{array}$

56

45,0

17,7

6,5

27
32,3
8,4
3,1

136

38,1

42,9

15,7

59

46,9

14,3

6,8

42
51,1
10,2
4,8

167

46,7

40,5

19,2

$\%$ fila $\ldots \begin{array}{llll} & \ldots & \ldots & \ldots\end{array}$

Profesionales subordinados (semiprofesiones)

Absolutos ... ... ... ...

$\%$ columna $\ldots$...

$\begin{array}{llllll}\% & \text { fila } \ldots & \ldots & \ldots & \ldots & \ldots\end{array}$

$\begin{array}{llllll}\% & \text { tabla } & \ldots & \ldots & \ldots & \ldots\end{array}$

Total

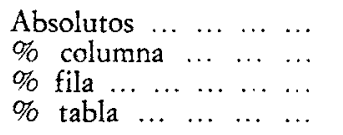

125

100,0

14,4

14,4

$\begin{array}{rr}10 & 14 \\ 8,1 & 16,6 \\ 7,3 & 9,9 \\ 1,2 & 1,6\end{array}$

54
15,2
39,3
6,3

Técnicos

18
28,8
5,6
2,1

$\begin{array}{rr}80 & 317 \\ 33,5 & 36,6 \\ 25,4 & 100,0 \\ 9,3 & 36,6\end{array}$

Absten-

cionistas Total 
TABLA IIIC

Profesionales, semiprofesionales y técnicos

Científicos, ingenieros $y$ otras profesiones rradicionales

Absolutos ...........

Frecuencia esperada ...

$\begin{array}{llll}\text { Residuos } & \ldots & \ldots & \ldots\end{array}$

Residuos estandarizados
Residuos ajustados . ...

RECUERDO VOTO GENERALES DEL 86

\begin{tabular}{l}
$\begin{array}{c}A P . P D P- \\
P L\end{array}$ CDS PSOE \\
\hline
\end{tabular}

Técnicos

Absolutos ... $\ldots . \ldots \ldots$

Frecuencia esperada ...

Residuos $\ldots \ldots \ldots$......

Residuos estandarizados

$\begin{array}{rr}56 & 27 \\ 45,8 & 30,1 \\ 10,5 & -3,5 \\ 1,6 & -0,6 \\ 2,1 & -0,8\end{array}$

$\begin{array}{rrr}136 & 18 & 80 \\ 130,8 & 22,8 & 87,9 \\ 5,3 & -4,9 & -7,4 \\ 0,5 & -1,0 & -0,8 \\ 0,8 & -1,3 & -1,2\end{array}$

317

317

0

-

Residuos ajustados ....

59

42

167

30

113

$29,5 \quad 113,8$

$\begin{array}{lllll}-0,7 & 3,0 & -2,7 & 0,9 & -0,5 \\ -0,1 & 0,5 & -0,2 & 0,2 & -0,0\end{array}$

411

411

$0,2 \quad-0,1$

$-0,1$

$0,7 \quad-0,4$

-

Profesionales subordinados (semiprofesiones)

Absolutos ... ... ...... Frecuencia esperada ... Residuos ... ... ... ...

Residuos estandarizados

Residuos ajustados . ...

$\begin{array}{rrr}10 & 14 & 54 \\ 20,0 & 13,1 & 57,0 \\ -9,8 & 0,5 & -2,6 \\ -2,2 & 0,1 & -0,3 \\ -2,6 & 0,2 & -0,5\end{array}$

$\begin{array}{rrr}14 & 46 & 138 \\ 9,9 & 38,3 & 138 \\ 4,0 & 7,9 & 0 \\ 1,3 & 1,3 & - \\ 1,4 & 1,6 & -\end{array}$

Total

\begin{tabular}{lrrrrrrr} 
Absolutos ........... & 125 & 82 & 357 & 62 & 240 & 867 \\
Frecuencia esperada . ... & 125 & 82 & 357 & 62 & 240 & 867 \\
Residuos ... ... . ... & 0 & 0 & 0 & 0 & 0 & 0 \\
Residuos estandarizados & - & - & - & - & - & - \\
Residuos ajustados . ... & - & - & - & - & - & - \\
\hline
\end{tabular}

$x^{2}=13,25361$

Grados de libertad $=8$

Significación $=0,1034$

la tabla IIIE refuta esta hipótesis para el PP. Este partido obtiene un apoyo significativo en la segunda categoría y es rechazado en la tercera.

Sin duda, el reducido tamaño de la primera categoría (Grandes Propietarios y Directivos), en relación al de las otras dos, explica en parte este hecho. Los Propietarios y Directivos constituyen menos de la décima parte del tamaño de cada una de las otras dos. Pero, a pesar de ello, creemos que la marcada diferencia entre las dos últimas categorías de la tabla IIIE y del 
TABLA IIID

RECUERDO VOTO GENERALES DEL 86

\begin{tabular}{ccccc}
$\begin{array}{c}A P-P D P \\
P L\end{array}$ & $C D S$ & $P S O E$ & $I U$ & $\begin{array}{c}\text { Absten- } \\
\text { cionistas }\end{array}$ \\
\hline
\end{tabular}

Directivos, propietarios

$y$ administrudores

Grandes propietarios y directivos

Absolutos $\ldots \ldots \ldots \ldots$

$\%$ columna $\ldots \ldots$...

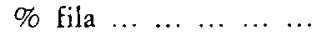

$\%$ tabla $\quad \ldots \begin{array}{llll} & \ldots & \ldots & \ldots\end{array}$

$\begin{array}{rrrrrr}23 & 6 & 25 & 1 & 18 & 73 \\ 6,4 & 3,1 & 3,1 & 1,7 & 5,8 & 4,2 \\ 31,9 & 7,6 & 33,9 & 1,7 & 25,0 & 100,0 \\ 1,4 & 0,3 & 1,4 & 0,1 & 1,1 & 4,2\end{array}$

Pequeños propietarios y administradores de nivel medio

Absolutos $\ldots \ldots \ldots$.....

$\%$ columna $\ldots \ldots \ldots$

$\%$ fila $\ldots \ldots \ldots c \ldots$

\section{8}

$\begin{array}{rr}92 & 383 \\ 50,9 & 48,6 \\ 10,7 & 44,5 \\ 5,3 & 22,2\end{array}$

31

147

860

57,2

24,1

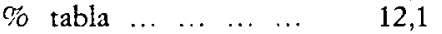

$5,3 \quad 22,2$

42,0

46,2

49,9

$3,5 \quad 17,1 \quad 100,0$

$1,8 \quad 8,5 \quad 49,9$

Administradores de nivel inferior

Absolutos ............

$\%$ columna $\ldots \ldots \ldots$

$\begin{array}{cccccc}\% & \text { fila } \ldots & \ldots & \ldots & \ldots & \ldots\end{array}$

$\begin{array}{llllll}\% & \text { tabla } & \ldots & \ldots & \ldots & \ldots \\ & & & & & \end{array}$

132

36,4

83

381

$46,0 \quad 48,3$

16,8

10,5

48,3
48,2

7,7

4,8

22,1

$\begin{array}{rr}41 & 152 \\ 56,3 & 48,0 \\ 5,2 & 19,3 \\ 2,4 & 8,8\end{array}$

790

45,8

100,0

45,8

Total

\begin{tabular}{|c|c|c|c|c|c|c|}
\hline Absolutos & 363 & 181 & 789 & 73 & 317 & 1.723 \\
\hline$\%$ columna & 100,0 & 100,0 & 100,0 & 100,0 & 100,0 & 100,0 \\
\hline$\%$ fila $\ldots \ldots \ldots \ldots \ldots$ & 21,1 & 10,5 & 45,8 & 4,2 & 18,4 & 100,0 \\
\hline \% tabla $\ldots \ldots \ldots$ & 21,1 & 10,5 & 45,8 & 4,2 & 18,4 & 100,0 \\
\hline
\end{tabular}

diagrama 2B, representa un hallazgo de interés. Los resultados apuntan a la conveniencia de descomponer la segunda categoría, agrupando a todos los Propietarios en una sola categoría y a todos los Administradores en otra. Obviamente, esto sugiere la importancia de la clase social -en la concepción marxista del término-, al menos en lo que respecta a los que son propietarios. Si los administradores en su conjunto se comportaran tal y como sucede en nuestros datos para la categoría de Administradores de nivel inferior, es decir, rechazando al PP y apoyando, en cierta medida, al PSOE (aunque esto está menos claro en nuestros datos), se confirmarían los resultados de nuestro análisis inicial sobre la situación de mercado o la División del 
TABLA IIIE

Directivos, propietarios

$y$ administradores

Grandes propietarios y directivos

Absolutos ............

Frecuencia esperada ...

Residuos $\ldots \ldots$........

Residuos estandarizados

Residuos ajustados....

RECUERDO VOTO GENERALES DEL 86

\begin{tabular}{l}
$\begin{array}{c}A P \cdot P D P \\
P L\end{array}$ CDS PSOE IU \\
\hline
\end{tabular}

Pequeños propietarios $y$ administradores de nivel medio

Absolutos .............

Frecuencia esperada ...

$\begin{array}{llll}\text { Residuos } & \ldots & \ldots & \ldots \\ \text { Residuos estandarizados }\end{array}$

Residuos ajustados ....

$\begin{array}{rrrrrr}23 & 6 & 25 & 1 & 18 & 73 \\ 15,4 & 7,7 & 33,4 & 3,1 & 13,5 & 73 \\ 7,9 & -2,1 & -8,7 & -1,8 & 4,8 & 0 \\ 2,0 & -0,8 & -1,5 & -1,1 & 1,3 & - \\ 2,3 & -0,8 & -2,1 & -1,1 & 1,5 & -\end{array}$

Administradores de nivel inferior

Absolutos ............

Frecuencia esperada ...

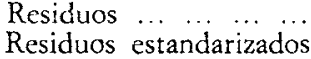

Residuos estandarizados
Residuos ajustados . ...

132

166,5

$-34,2$

$-2,7$

$-4,1$

$\begin{array}{rr}83 & 381 \\ 82,9 & 361,6 \\ 0,3 & 19,4 \\ 0,0 & 1,0 \\ 0,1 & 1,9\end{array}$

41
33,3
7,6
1,3
1,8

Total

\begin{tabular}{|c|c|c|c|c|c|c|}
\hline Absolutos ... & 363 & 181 & 789 & 73 & 317 & 1.723 \\
\hline Frecuencia esperada ... & 363 & 181 & 789 & 73 & 317 & 1.723 \\
\hline Residuos ... & 0 & 0 & 0 & 0 & 0 & 0 \\
\hline Residuos estandarizados & - & - & - & - & - & — \\
\hline Residuos ajustados .... & - & 一 & 一 & - & 一 & - \\
\hline
\end{tabular}

$x^{2}=25,76773$

Grados de libertad $=8$

Significación $=0,0012$

Trabajo en la Sociedad. Recordemos que el PP estaba extremadamente arraigado entre los trabajadores por cuenta propia, mientras que el PSOE contaba con un fuerte apoyo entre los asalariados fijos (que incluirían a la mayoría de los administradores). Por lo tanto, estos datos, considerados en conjunto, sugieren que la situación de mercado puede ser un determinante más poderoso del apoyo partidista que la posición en el mercado, al menos para este segmento de la población asalariada. 
DIAGRAMA 2B

Raices sociales de los partidos en la División Industrial del Trabajo

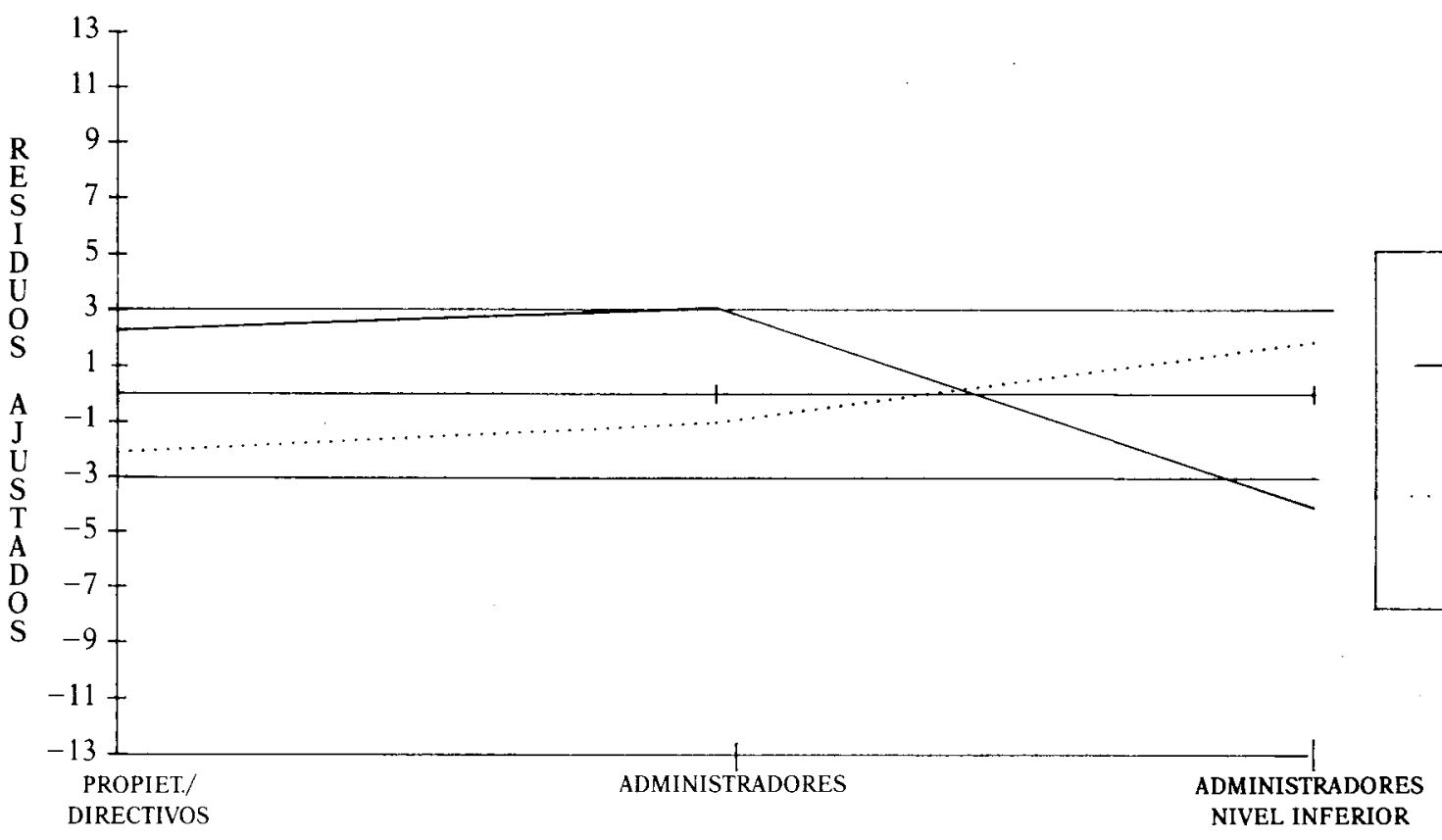

\author{
OCUPACION \\ (DIRECTIVOS, PROPIETARIOS \\ Y ADMINISTRADORES) \\ POBLACION ACTIVA (EXCLUIDA AYUDA FAMILIAR)
}


Los niveles de cualificación y la distinción entre trabajadores de «cuello blanco» $y$ «cuello azul»

Como ya hemos señalado en la presentación y discusión de las variables independientes, la codificación de las tres categorias de la variable ocupación que diferencian a los trabajadores por su nivel de cualificación incluía la distinción entre trabajadores de cuello blanco y cuello azul. Dado el importante significado tradicional asignado a esta distinción en sociología, obviamente nos interesa examinar el problema con mayor profundidad. Esta especificación difiere de la realizada en las dos primeras categorías (Profesionales, etc., y Propietarios y Directivos) en que añade una variable nueva: tipología por actividad.

Decidimos que la forma más apropiada de examinar esta triple relación entre: 1) trabajadores de cuello blanco/azul, 2) nivel de cualificación y 3) apoyo partidista, era tratar el contenido del trabajo (manual o no manual) como la variable de clasificación y, después, analizar los cruces entre el nivel de cualificación y el apoyo partidista.

Las tablas IIIF y IIIG presentan los datos y residuos ajustados para la subtabla: Nivel de Cualificación por Voto. Introducimos estas tablas porque el análisis del contenido del trabajo constituye una descomposición de esta relación.

Aunque el Gi-cuadrado total de la tabla IIIG es bastante significativo, los RA sólo muestran, por el contrario, algunos resultados interesantes, a saber: las diferencias entre los trabajadores semicualificados y los no cualificados. El CDS tiene un arraigo débil y significativo $(0,05)$ entre los primeros, quienes, además, tienden a participar significativamente en el proceso electoral. Los trabajadores no cualificados, por el contrario, rechazan débilmente a este partido y, además, se abstienen significativamente.

La descomposición del cruce entre el nivel de cualificación y el recuerdo de voto por las categorías de cuello blanco y cuello azul no añade apenas nada nuevo a la información presentada en el párrafo anterior. Un problema importante es que sólo el 19 por 100 de los trabajadores definidos por su nivel de cualificación son de cuello blanco y que el 60 por 100 de ellos se concentra en ocupaciones semicualificadas. Por lo tanto, hemos incluido en un apéndice las tablas IIIH-IIIK y los diagramas $2 \mathrm{C}-2 \mathrm{~F}$ donde se presentan estos datos.

Solamente el Gi-cuadrado correspondiente a la subtabla de los trabajadores de cuello azul es significativo a un nivel superior al 0,01. Limitamos los resultados a la comparación entre los trabajadores semicualificados y los no cualificados de cuello azul, que corroboran los que acabamos de describir para los tres niveles ocupacionales. Por supuesto, la ausencia de diferencias sustanciales entre los trabajadores de cuello blanco y cuello azul en esos tres 


\section{TABLA IIIF}

RECUERDO VOTO GENERALES DEL 86

\begin{tabular}{|c|c|c|c|c|}
\hline $\begin{array}{c}A P-P D P- \\
P L\end{array}$ & $C D S$ & PSOE & $I U$ & $\begin{array}{l}\text { Absten- } \\
\text { cionistas }\end{array}$ \\
\hline
\end{tabular}

Trabajadores cualificados,

\section{semicualificados,}

\section{no cualificados}

Supervisores, capataces y

trabajadores cualifica-

dos

\begin{tabular}{|c|c|c|c|c|c|c|}
\hline Absolutos & 120 & 117 & 800 & 100 & 182 & 1.318 \\
\hline$\%$ columna & 31,8 & 31,1 & 31,5 & 29,7 & 29,5 & 31,1 \\
\hline$\%$ fila $\ldots \ldots \ldots$ & 9,1 & 8,8 & 60,7 & 7,6 & 13,8 & 100,0 \\
\hline$\%$ tabla $\ldots$ & 2,8 & 2,7 & 18,8 & 2,3 & 4,3 & 31,1 \\
\hline
\end{tabular}

Trabajadores semicualifica-

dos

\begin{tabular}{|c|c|c|c|c|c|c|}
\hline Absolutos $\ldots \ldots \ldots$ & 136 & 158 & 925 & 127 & 190 & 1.535 \\
\hline$\%$ columna & 36,0 & 42,0 & 36,4 & 37,9 & 30,8 & 36 \\
\hline$\%$ fila ... .. & 8,9 & 10,3 & 60,2 & 8,3 & 12,4 & 100 \\
\hline$\%$ tabla $\ldots \begin{array}{lllll} & \ldots & \ldots & \ldots & \ldots\end{array}$ & 3,2 & 3.7 & 21,8 & 3,0 & 4,5 & \\
\hline
\end{tabular}

Trabajadores no cualificados

$\begin{array}{lllllrrrrrr}\text { Absolutos } \ldots & \ldots & \ldots & \ldots & 122 & 101 & 815 & 108 & 245 & 1,392 \\ \% \text { columna } & \ldots & \ldots & \ldots & 32,2 & 27,0 & 32,1 & 32,4 & 39,7 & 32,8 \\ \% \text { fila } \ldots & \ldots & \ldots & \ldots & \ldots & 8,7 & 7,3 & 58,6 & 7,8 & 17.6 & 100,0 \\ \% \text { tabla } \ldots & \ldots & \ldots & \ldots & \ldots & 2.9 & 2,4 & 19,2 & 2,6 & 5,8 & 32,8\end{array}$

Total

\begin{tabular}{|c|c|c|c|c|c|c|}
\hline Absolutos & 378 & 375 & 2.540 & 335 & 617 & 4.245 \\
\hline$\%$ columna $\ldots$ & 100,0 & 100,0 & 100,0 & 100,0 & 100,0 & 100,0 \\
\hline $\begin{array}{llll}\ldots & \ldots & \ldots & \ldots\end{array}$ & 8,9 & 8,8 & 59,8 & 7,9 & 14,5 & 100,0 \\
\hline$\%$ tabla $\ldots \ldots c c c c$ & 8,9 & 8,8 & 59,8 & 7,9 & 14,5 & 100,0 \\
\hline
\end{tabular}

niveles de cualificación apoya las decisiones tomadas en el proceso de codificación de la variable ocupación.

\section{Ocupación y apoyo partidista. Recapitulación}

En cierta ocasión se ha dicho que el estudio de las relaciones entre las ocupaciones y el apoyo partidista es como volver a descubrir América. Sin duda, 


\section{TABLA IIIG}

RECUERDO VOTO GENERALES DEL 86

Trabajadores cualificados, semicualificados,

no ctialificados

Supervisores, capataces $y$ trabajadores cualifica-

dos

Absolutos ... $\ldots . . . . .$.

$\begin{array}{rrrrrr}120 & 117 & 800 & 100 & 182 & 1.318 \\ 117,4 & 116,6 & 788,7 & 104,0 & 191,5 & 1.318 \\ 2,9 & 0,1 & 11,2 & -4,5 & -9,7 & 0 \\ 0,3 & 0,0 & 0,4 & -0,4 & -0,7 & - \\ 0,3 & 0,0 & 0,8 & -0,6 & -0,9 & -\end{array}$

Trabajadores semicualificados

Absolutos ..............

Frecuencia esperada ...

136

158

$136,6 \quad 135,8$

925

127

\begin{tabular}{l}
$\begin{array}{c}\text { AP.PDP. } \\
P L\end{array}$ CDS PSOE IU \\
\hline
\end{tabular}

Residuos $\ldots$... ... ...

$-0,5$

21,8

Residuos estandarizados

$-0,0$

1,9

918,4

121,1

190

1.535

$-0,1$

6,1

5,

0,2

223,0

1.535

Residuos ajustados ....

2,4

0,4

0,5

$0,7 \quad-3,0$

Trabajadores no cualificados

Absolutos ............

Frecuencia esperada ...

$\begin{array}{rrrrr}101 & 815 & 108 & 245 & 1.392 \\ 123,1 & 832,6 & 109,8 & 202,2 & 1.392 \\ -21,8 & -17,3 & -1,3 & 42,9 & 0 \\ -2,0 & -0,6 & -0,1 & 3,0 & - \\ -2,5 & -1,2 & -0,2 & 4,0 & -\end{array}$

$\begin{array}{lllll}\text { Residuos } & \ldots & \ldots & \ldots & \ldots \\ \text { Residuos } & \text { estandarizados }\end{array}$

1239

123,9

$-2,4$

$-0,2$

$-2,5$

$\begin{array}{rrr}378 & 375 & 2.540 \\ 378 & 375 & 2.540 \\ 0 & 0 & 0 \\ - & - & - \\ - & - & -\end{array}$

$\begin{array}{lllll}\text { Frecuencia } & \text { esperada } & \ldots \\ \text { Frolutos } & \ldots & \ldots & \ldots & \ldots \\ & & & & \end{array}$

Residuos $\ldots$... $\quad \ldots$...

Residuos estandarizados

Residuos ajustados ....

$x^{2}=23,04029$

Grados de libertad $=8$

Significación $=0,0033$

esto es parcialmente cierto. Pero hay que recordar, entonces, que esto es precisamente lo que hizo Colón. La diferencia entre los Vikingos y Colón no radica en quiénes fueron los primeros en divisar el continente, sino en el nivel de detalle, la riqueza de la descripción y, sobre todo, la capacidad de 
analizar las sutilezas y complejidades, en este caso, de las relaciones sociales.

Nos referiremos de nuevo al diagrama 2 para resumir los resultados referentes a los cuatro partidos, especialmente a los dos más pequeños: el CDS e IU. Respecto al CDS, nuestros resultados indican que este partido carece de arraigos en todas las categorías ocupacionales importantes y que es rechazado al nivel de significación por los trabajadores no cualificados. Estos resultados son consistentes con los obtenidos en el análisis de la situación de mercado.

Aunque IU es rechazada en las dos categorías de Propietarios y Administradores, el nivel de rechazo es considerablemente más bajo que el del PSOE. Sin embargo, esta coalición sólo encuentra un apoyo significativo entre los trabajadores semicualificados, mucho más débil del que posee el PSOE en los tres niveles de cualificación. IU presenta más variaciones que el CDS, aunque ambos partidos carecen casi por completo de raíces en la estructura ocupacional. Por último, en las categorías de Administradores de nivel inferior y Artesanos los cuatro partidos se muestran competidores entre sí.

Considerando ahora a los dos partidos más importantes, como se recoge en el diagrama $2 \mathrm{~A}$, el resultado más obvio lo constituye la simetría inversa de raíces y rechazos. La excepción la constituyen los Profesionales Tradicionales, que rechazan al PSOE sin mostrar simultáneamente ningún apoyo al PP. Entre los Propictarios, el arraigo del PP es más fuerte que el rechazo al PSOE. Lo contrario ocurre en las tres categorías definidas por el nivel de cualificación: el arraigo del PSOE es ligeramente más débil que el rechazo al PP.

Los análisis de la subtabla añaden alguna información a lo anterior. Así, la ausencia de arraigos entre los Profesionales Tradicionales parece estar relacionada, en el caso del PP, con el rechazo que recibe este partido por parte de los Subprofesionales. Del mismo modo, el fracaso del PP para encontrar apoyo entre los Administradores se explica por el rechazo que recibe en la categoría más baja del nivel administrativo. Por último, la diferencia entre trabajadores manuales (de «cuello azul») y no manuales (de «cuello blanco»), en las tres categorías del nivel de cualificación, no añade ninguna información.

\section{La División del Trabajo por sectores económicos}

En el gráfico 3 se presenta una panorámica general de la División del Trabajo Sectorial. Conviene observar que, según nuestra muestra, casi la mitad de los empleos en España pertenecen al Sector Servicios generado por 
el sector privado de la economía. Aunque la economía española ha experimentado una modernización considerable en las dos últimas décadas, el sector agrario todavía comprende más del 10 por 100 del total. Por lo tanto, creemos que el tamaño del Sector Servicios de la empresa privada refleja la importancia de la industria turística, la pervivencia de un gran número de empresas pequeñas y poco capitalizadas -quizá incluso poco racionalizadas-, además de un segmento creciente de servicios financieros, grandes y extremadamente racionalizados.

Las tablas IV y IVA presentan los porcentajes y residuos ajustados, respectivamente. Respecto a la abstención, tanto el Sector Agrario como el Industrial participan electoralmente a un nivel significativo, mientras que la no participación tiende sus raíces en el Sector Servicios de la empresa privada.

El diagrama 3 presenta los resultados por sectores de una forma visualmente más clara, razón por la que nuestros comentarios sobre el tema están basados en el diagrama y no en la tabla IVA.

Los resultados para los cuatro partidos muestran de nuevo una simetría inversa respecto a los dos primeros sectores, la Agricultura y la Industria. En cuanto al Sector Agrario, los dos partidos menos importantes carecen de tendencias significativas. Sin embargo, mientras que el PP está extremadamente arraigado en la Agricultura, el nivel de rechazo al PSOE es tan sólo significativo en este sector. Cuando analizamos el Sector Industrial se produce una mayor diferenciación entre los dos partidos minoritarios, observándose un arraigo significativo de IU en el sector. Los dos partidos principales no están tan diferenciados como en el Sector Agrario: tanto el arraigo del PSOE como el rechazo al PP son significativos. Por supuesto que el Sector Industrial es casi el doble, en tamaño, que el Sector Agrario.

El PSOE está arraigado significativamente en el Sector de la Construcción, e IU es rechazada en el Sector Servicios de la empresa privada. Los otros tres partidos compiten fuertemente en este sector, que es el mayor de todos. Sospechamos que la heterogeneidad del sector es la causa de la ausencia de una mayor diferenciación entre los partidos, pero estos datos no permiten una ulterior descomposición. Respecto al Sector Servicios generado por el sector público de la economía, observamos un arraigo significativo de IU y un rechazo, también significativo al PSOE. El CDS está arraigado significativamente, mientras que al PP se le rechaza a un nivel de significación del 0,05 .

Insistiendo de nuevo en lo ya dicho en otras partes, el CDS se muestra, comparativamente, bastante débil, tanto en raíces como en rechazos. IU, sin embargo, extiende sus raíces a dos de los sectores, Industria y Servicios (Administración Pública), y obtiene un fuerte rechazo en un sector extremadamente grande, el Sector Servicios de la empresa privada. 
Rama de actividad. Población activa (excluida Ayuda Familiar)

(Distribución porcentual)

AGRIC./GAN./ PESCA

INDUSTRIA

CONSTRUC.

SERVICIOS

E. PRIVADA

SERVICIOS

E. PUBLICA

45,6 
TABLA IV

\section{Rama de actividad}

Agricultura, ganadería y pesca

Absolutos ... $\ldots \ldots \ldots$

$\%$ columna $\ldots \ldots \ldots$

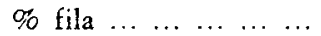

of tabla $\ldots \begin{array}{llll} & \ldots & \ldots & \ldots\end{array}$

$\begin{array}{rrrrrr}217 & 95 & 409 & 52 & 96 & 868 \\ 19,3 & 12,8 & 9,9 & 10,4 & 7,5 & 11,2 \\ 25,0 & 10,9 & 47,1 & 5,9 & 11,1 & 100,0 \\ 2,8 & 1,2 & 5,3 & 0,7 & 1,2 & 11,2\end{array}$

Industria

Absolutos ... $\ldots . \ldots \ldots$

$\%$ columna $\ldots \ldots \ldots$

174

15,4

122

11,4

16,5

900

131

191

Absten-

$\%$ fila $\ldots \ldots \ldots c c c c$

11,4
2,2

$8,0 \quad 59,3$

21,8

26,4

15,0

1.517

8,6

19,6

$1,6 \quad 11,6$

1,7

$\begin{array}{rr}12,6 & 100,0 \\ 2,5 & 19,6\end{array}$

Construcción

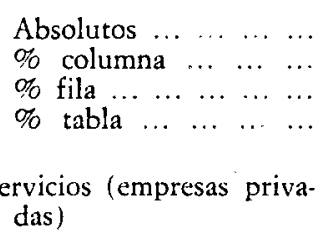

Absolutos ... ... ... ...

$\begin{array}{ccccc}\% & \text { columna } & \ldots & \ldots & \ldots \\ \% & \text { fila } \ldots & \ldots & \ldots & \ldots \\ \% & \ldots & \ldots\end{array}$

512

74

59

378

36

87

633

6,6
11,6

8,1

9,2

7,2

6,8

8,2

1.0

9,4
0,8

59,7

5,6

13,7

100,0

$\begin{array}{rrrr}4,9 & 0,5 & 1,1 & 8,2\end{array}$

45,5

323

1.864

167

672

3.537

14,5

43,7

45,2

33,8

52,8

19,0

6,6

$9,1 \quad 52,7$

4,7

8,7

100,0

45,6

Servicios (Administraciones públicas)

Absolutos ... ... $\ldots . .$.

$\%$ columna $\ldots \ldots \ldots c$

149

140

568

110

227

17,9

19,0

1.195

13,3

18,9

13,8

22,2

15,4

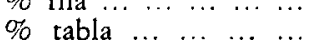

12,5
1,9

1,8
1,7

47,6
7,3

1,4

100,0

15,4

Total

\begin{tabular}{|c|c|c|c|c|c|c|}
\hline Absolutos & 1.125 & 738 & 4.119 & 495 & 1.273 & 7.750 \\
\hline$\%$ columna & 100,0 & 100,0 & 100,0 & 100,0 & 100,0 & 100,0 \\
\hline$\%$ fila & 14,5 & 9,5 & 53,1 & 6,4 & 16,4 & 100,0 \\
\hline$\%$ tabla $\ldots . .$. & 14,5 & 9,5 & 53,1 & 6,4 & 16,4 & 100,0 \\
\hline
\end{tabular}


TABLA IVA

Rama de actividad

Agricultura, ganadería y pesca

Absolutos ... . . . ... ...

Frecuencia esperada ...

Residuos ... ... ... ...

Residuos estandarizados

Residuos ajustados . ...

Industria

Absolutos $\ldots \ldots \ldots \ldots$

Frecuencia esperada ...

Residuos ... ... ... ...

Residuos estandarizados

Residuos ajustados

Construcción

Absolutos $\ldots \ldots \ldots \ldots$

Frecuencia esperada ...

Residuos $\ldots . . . \ldots \ldots$
Residuos estandarizados

Residuos ajustados ...

Servicios (empresas privadas)

Absolutos . . . . . . . . ...

Frecuencia esperada ...

Residuos ... ... ... ...

Residuos estandarizados

Residuos ajustados ....

Servicios (Administracio-

nes públicas)

Absolutos ... ... ......

Frecuencia esperada ...

Residuos ... ... ... ...

Residuos estandarizados

Residuos ajustados ....

Total

Absolutos ............

Frecuencia esperada ...

Residuos

Residuos estandarizados

Residuos ajustados ....
RECUERDO VOTO GENERALES DEL 86

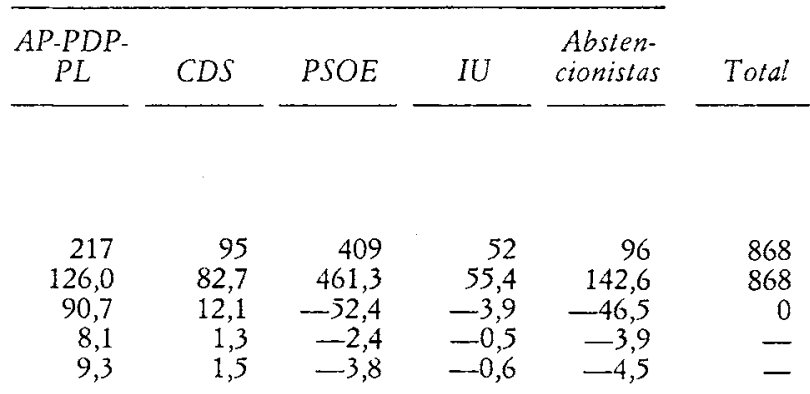

174

220,2

$-46,6$

$-3,1$

$-3,8$
122

144,5

$-22,6$

$-1,9$

$-2,2$

74

92,0

$-18,2$

$-1,9$

$-2,1$

59

60,3

$-0,9$

0,1
$-0,1$
323

336,9

336,9
$-14,4$
$--0,8$

$-0,8$
$-1,1$

1.864

$1.879,8$

$-16,3$

$-0,4$

378

336,6

41,5

2,3

3,5
131

96,8

33,7

$$
3,4
$$

4,0
191

249,2

$-58,1$

$-3,7$

$-4,5$

36

40,4

$-4,9$

$-0,8$
$-0,8$

87

633

633

$-17,6$

$-1,7$

$-2,8$
167

225,7

$-58,7$

$-3,9$

$-0,1$

$-1$

149

173,4

140

568

634,9

$-66,5$

$-2,6$

$-24,1$
$-1,8$

25,8

2,4

$-2,2$

2,8

$-4,2$

$\begin{array}{rr}110 & 227 \\ 76,2 & 196,2 \\ 33,7 & 31,2 \\ 3,9 & 2,2 \\ 4,3 & 2,6\end{array}$

1.195

1.195

0

2,2

581,1

3.537

3.537

91,0

5,6

0

$x^{2}=216,51481$

Grados de libertad $=16$

Significación $=0,0000$ 
Raices sociales de los partidos en los sectores productivos

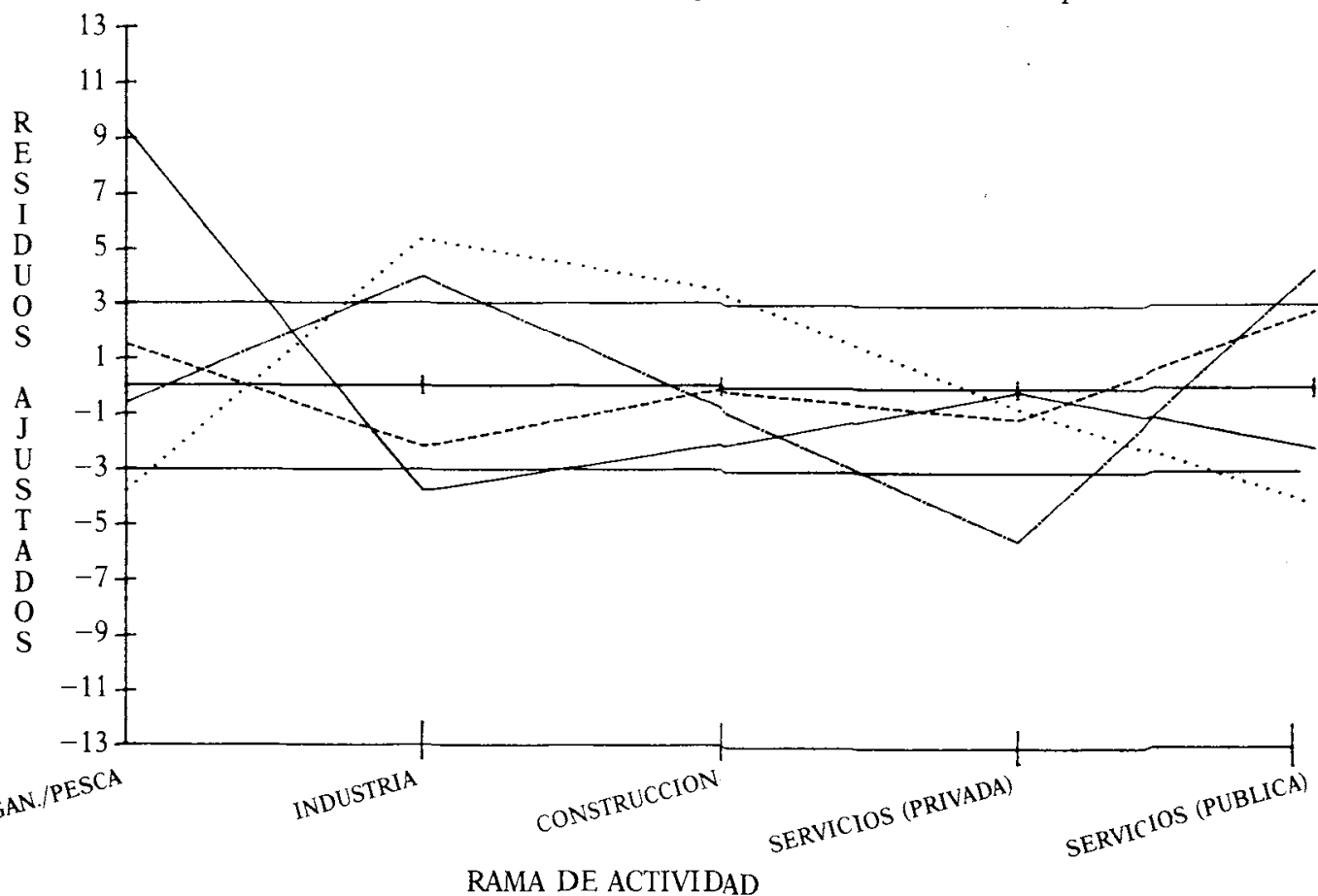

$-\mathrm{AP} / \mathrm{PDP} / \mathrm{PL}$

-- CDS

PSOE

... IU

POBLACION ACTIVA (EXCLUIDA AYUDA FAMILIAR) 
Raices sociales de los partidos en los sectores productivos

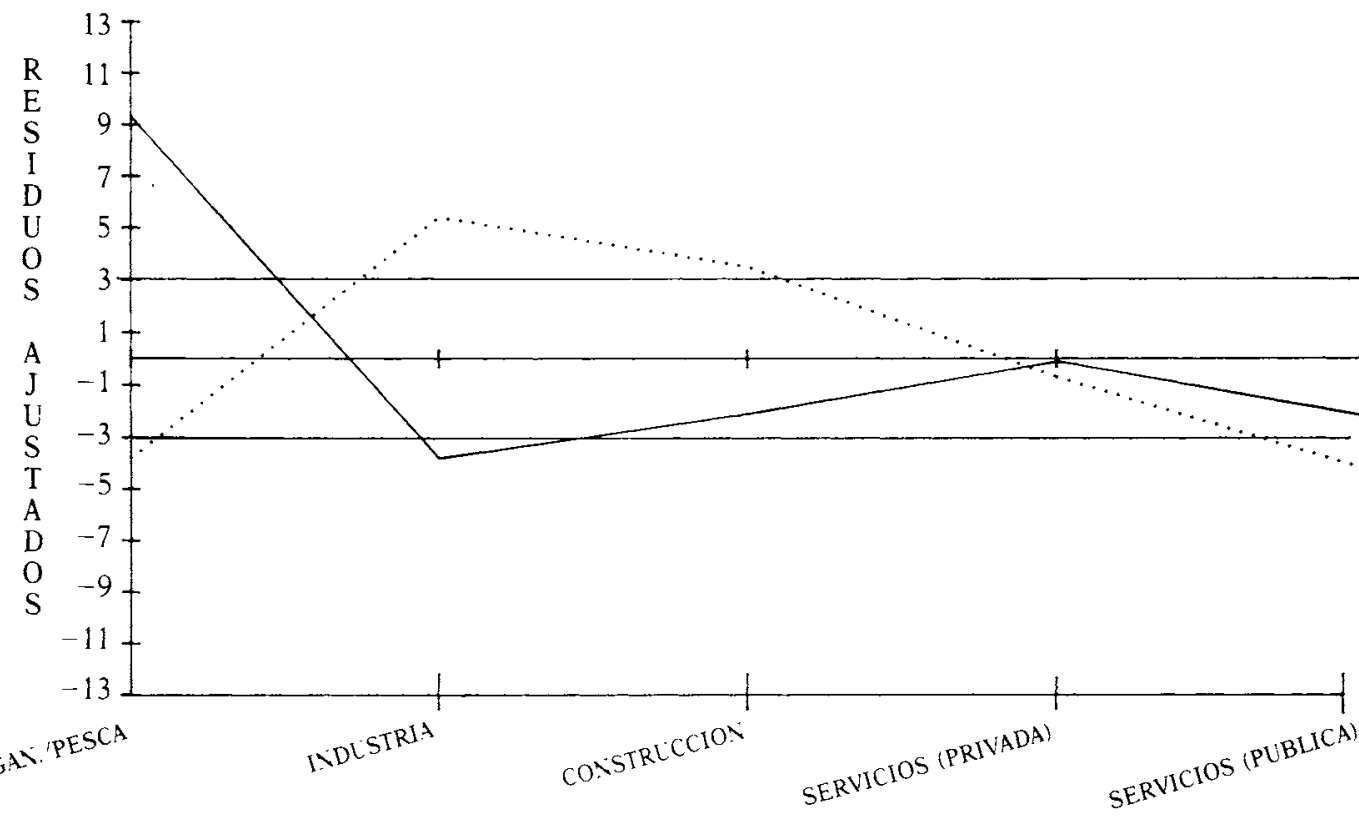

- $\mathrm{AP} / \mathrm{PDP} / \mathrm{PL}$

RAMA DE ACTIVIDAD

POBLACION ACTIVA (EXCLLIDA AYLDA FAMILIAR)

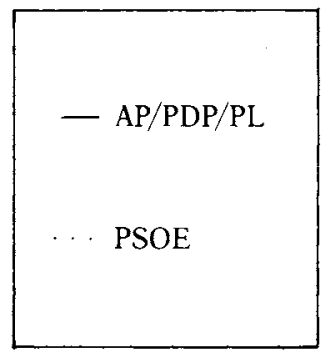


La comparación entre los dos partidos principales en el diagrama 3A, repite el modelo de raíces y rechazos descrito anteriormente.

Resumen de la División del Trabajo por Sectores Económicos

Los resultados del análisis de la relación entre la División del Trabajo Sectorial y el Apoyo Partidista son menos informativos que los obtenidos en las otras dos dimensiones de la División del Trabajo: la Situación de Mercado y la Posición en el Mercado. Reiteramos nuestra sospecha de que el problema radica en la heterogeneidad de las categorías, especialmenté en el caso del Sector Servicios de la empresa privada. Por lo tanto, preferimos ser prudentes ante posibles interpretaciones forzadas de los datos. Por ejemplo, aunque los datos indican que en el sector más grande, con casi la mitad de la muestra utilizada, existe gran competitividad entre los dos partidos principales, ya hemos comentado que puede deberse más a la heterogeneidad del sector y a que algunas diferencias reales pueden quedar ocultas. En próximos análisis esperamos poder descomponer este sector.

\section{CONCLUSIONES}

Comenzaremos estas conclusiones refiriéndonos nuevamente a la diferencia entre el análisis de las magnitudes absolutas y relativas del apoyo partidista en cualquier categoría de la División del Trabajo, y los Residuos Ajustados de las celdillas (RA). Repitiendo lo ya expuesto, diremos que los segundos estiman el excedente o déficit de cualquier celdilla respecto a su probabilidad marginal de apoyo o rechazo. Se puede usar la metáfora de la intensidad, en lugar de la cantidad, para caracterizar la diferencia entre los dos tipos de estimaciones y análisis. De este modo, el arraigo de un partido en una categoría concreta puede reflejar un intenso nivel de apoyo, incluso para un tamaño muy pequeño de celdilla observada. Dicho análisis reporta utilidad si añade información al escrutinio del tamaño y el porcentaje de las celdillas. Creemos que así sucede. La nueva información tiene que ver con la firmeza y continuidad de los apoyos. El arraigo en una categoría, incluso cuando está basado en un valor absoluto moderado, indica que, al menos para esa categoría, es probable que el nivel de apoyo perdure y no se erosione fácilmente.

Cualquier análisis que conlleve esta cantidad y detalle de datos plantea tantos interrogantes como respuestas. Un buen ejemplo es la ambigüedad de los arraigos, casi idénticos, de tres de los cuatro partidos respecto a las amas de casa (diagrama 1). Si este resultado se mantiene en análisis suce- 
sivos, la probabilidad, entonces, de que el PP o el CDS desafíen la hegemonía del PSOE, aumenta considerablemente. Si análisis posteriores pudieran demostrar que cuando esta categoría se descompone en partes (diferencias de edad, empleo anterior, posición del cónyuge, etc.) aumenta su heterogeneidad respecto al apoyo partidista, la amenaza de la competencia por alcanzar la posición hegemónica del PSOE puede disminuir considerablemente, dependiendo de los resultados obtenidos por dicha descomposición.

Un análisis con este nivel de detalle de un número pequeño de variables nunca está completo. Siempre hay cuestiones que hacen referencia a otras variables y subtablas adicionales. A modo de ejemplo, en este trabajo se ignora el problema del regionalismo, una fuerza que siempre ha influido en la vida política española a nivel nacional. Leo Goodman escribió una vez un artículo sobre este tipo de análisis titulado «Entrando a saco en las tablas de movilidad». La expresión «entrando a saco» es particularmente apropiada como descripción del proceso analítico e interpretativo. Las complejidades abundan y se oscurecen las tendencias globales más nítidas.

Gran parte de las interpretaciones de estos datos han sido presentadas en el cuerpo central de este trabajo, especialmente en las secciones resumidas de cada uno de los aspectos de la DT. En lo que sigue, por lo tanto, intentaremos establecer algunas conclusiones de carácter general.

La Situación de Mercado muestra la mayor diferenciación entre los cuatro partidos. Por ejemplo, es la única dimensión de la División del Trabajo donde el CDS presenta raíces y rechazos. Por otra parte, el Sector Económico resultó ser la menos informativa de las variables independientes. El análisis de la Posición en el Mercado u Ocupación destacó por la consistencia de sus resultados con los obtenidos para la Situación de Mercado. Observándose, además, en este aspecto de la DT, una nítida simetría inversa entre los dos partidos principales.

En cuanto a lo que hemos aprendido sobre los cuatro partidos nacionales, diríamos que el CDS es un partido sustancialmente desarraigado en las tres dimensiones de la División del Trabajo. Nuestros resultados sugieren, cuando menos, una posición débil para este partido en la política nacional. Y si la interpretación que hemos avanzado antes sobre el significado de los arraigos fuera correcta, este partido podría desaparecer con facilidad.

IU muestra una estructura mucho más diferenciada que el CDS. Sin embargo, existe la tendencia a que se constituya en sombra del PSOE en la mayoría de las categorías en que extiende sus raíces, como se observa en el diagrama II. Frecuentemente se trata de una sombra pálida, además de que el número de categorías donde la coalición está arraigada es más reducido. Creemos que, aunque estos resultados señalan como improbable la desaparición de IU, tampoco muestran la potencialidad de un fuerte creci- 
miento, necesario si se quiere competir con realismo por una posición hegemónica.

Pasando ahora a los dos principales partidos, los resultados más interesantes se relacionan con el «techo» que parece caracterizar al PP. Como se desprende de las interpretaciones contenidas en este trabajo, este techo se caracterizaría por dos aspectos. Primero, el nivel de rechazo al PP (en las categorías en que es rechazado) es muy alto. Es improbable que el PP modifique su atractivo para estas categorías. Segundo, sus arraigos están ubicados en categorías que son relativamente pequeñas en tamaño absoluto. Por lo tanto, y aunque el PP mantuviera sus apoyos en estas categorías, serían insuficientes para proporcionarle una base consistente desde la que alcanzar una posición hegemónica. Este es especialmente el caso cuando se consideran conjuntamente los dos efectos del techo.

Por último, basándonos en estos datos, muy limitados, pero ricos, no existen apenas argumentos que permitan defender la tesis de una probable pérdida de la posición hegemónica por parte del PSOE. EI CDS puede per fectamente disolverse, permaneciendo verosímilmente IU como una coalición nacional bastante pequeña; el PP posiblemente quede limitado a ocupar su posición actual, debido a los efectos del techo. La principal amenaza para el PSOE es probable que venga por una reducción en la magnitud del voto más que por un desafío proveniente de cualquiera de los otros partidos.

Existen pocos indicios en estos datos que permitan creer que el PSOE puede perder su posición de partido dominante debido al crecimiento de la fuerza de cualquiera de los otros tres partidos. De esto se desprendería que el futuro de las actuales bases de la estabilidad política en España reside en las acciones del PSOE, y que les corresponde a ellos el mantenerlas o perderlas. 


\section{APENDICE}

\section{TABLA IIIH}

\begin{tabular}{|c|c|c|c|c|c|c|}
\hline & \multicolumn{5}{|c|}{ RECUERDO VOTO GENERALES DEL 86} & \multirow[b]{2}{*}{ Total } \\
\hline & $\begin{array}{c}A P-P D P \\
P L\end{array}$ & $\operatorname{CDS}$ & PSOE & $I U$ & $\begin{array}{l}\text { Absten- } \\
\text { cianistas }\end{array}$ & \\
\hline \multicolumn{7}{|l|}{$\begin{array}{l}\text { Tipología por actividad } \\
\text { Trabajadores de cuello } \\
\text { blanco }\end{array}$} \\
\hline \multicolumn{7}{|l|}{$\begin{array}{l}\text { Trabajadores cualificados, } \\
\text { semicualificados, no } \\
\text { cualificados, superviso- } \\
\text { res, capataces y traba- } \\
\text { jadores cualificados }\end{array}$} \\
\hline 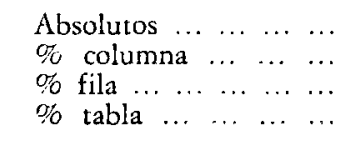 & $\begin{array}{r}19 \\
20,7 \\
13,7 \\
2,3\end{array}$ & $\begin{array}{r}16 \\
20,4 \\
11,9 \\
2,0\end{array}$ & $\begin{array}{r}69 \\
14,8 \\
50,6 \\
8,6\end{array}$ & $\begin{array}{r}10 \\
19,4 \\
7,3 \\
1,2\end{array}$ & $\begin{array}{r}23 \\
19,0 \\
16,5 \\
2,8\end{array}$ & $\begin{array}{r}137 \\
16,9 \\
100,0 \\
16,9\end{array}$ \\
\hline \multicolumn{7}{|l|}{$\begin{array}{l}\text { Trabajadores semicualifi- } \\
\text { cados }\end{array}$} \\
\hline 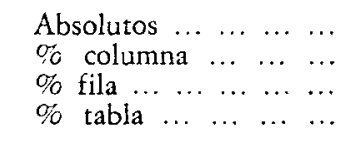 & $\begin{array}{r}50 \\
55,7 \\
10,3 \\
6,2\end{array}$ & $\begin{array}{r}46 \\
58,3 \\
9,5 \\
5,8\end{array}$ & $\begin{array}{l}296 \\
63,4 \\
60,7 \\
36,7\end{array}$ & $\begin{array}{r}30 \\
59,4 \\
6,3 \\
3,8\end{array}$ & $\begin{array}{r}65 \\
54,5 \\
13,3 \\
8,0\end{array}$ & $\begin{array}{r}487 \\
60,5 \\
100,0 \\
60,5\end{array}$ \\
\hline \multicolumn{7}{|l|}{$\begin{array}{l}\text { Trabajadores no cualifica- } \\
\text { dos }\end{array}$} \\
\hline 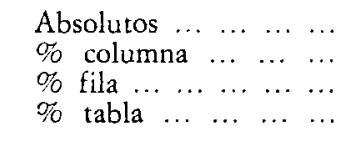 & $\begin{array}{r}21 \\
23,5 \\
11,7 \\
2,6\end{array}$ & $\begin{array}{r}17 \\
21,4 \\
9,3 \\
2,1\end{array}$ & $\begin{array}{r}101 \\
21,8 \\
55,7 \\
12,6\end{array}$ & $\begin{array}{r}11 \\
21,2 \\
6,0 \\
1,3\end{array}$ & $\begin{array}{r}31 \\
26,5 \\
17,3 \\
3,9\end{array}$ & $\begin{array}{r}182 \\
22,6 \\
100,0 \\
22.6\end{array}$ \\
\hline \multicolumn{7}{|l|}{ Total } \\
\hline $\begin{array}{cccccc}\text { Absolutos } & \ldots & \ldots & \ldots & \ldots \\
\% & \text { columna } & \ldots & \ldots & \ldots \\
\% & \text { fila } & \ldots & \ldots & \ldots & \ldots \\
\% & \text { tabla } & \ldots & \ldots & \ldots & \ldots \\
\%\end{array}$ & $\begin{array}{r}90 \\
100,0 \\
11,2 \\
11,2\end{array}$ & $\begin{array}{r}80 \\
100,0 \\
9,9 \\
9,9\end{array}$ & $\begin{array}{r}466 \\
100,0 \\
57,8 \\
57,8\end{array}$ & $\begin{array}{r}51 \\
100,0 \\
6,4 \\
6,4\end{array}$ & $\begin{array}{r}119 \\
100,0 \\
14,7 \\
14,7\end{array}$ & $\begin{array}{r}806 \\
100,0 \\
100,0 \\
100,0\end{array}$ \\
\hline
\end{tabular}


TABLA IIIi

Tipología por actividad

Trabajadores de cuello

blanco

Trabajadores cualificados, semicualificados, no cualificados, supervisores, capataces y trabajadores cualificados

Absolutos ... . . . . . ...

Frecuencia esperada ...

$\begin{array}{lllll}\text { Residuos } & \ldots & \ldots & \ldots & \ldots\end{array}$

Residuos estandarizados

Residuos ajustados ....

Trabajadores semicualificados

Absolutos ... .......... Frecuencia esperada ... Residuos ... ... ....... Residuos estandarizados Residuos ajustados ....

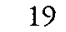

15,3

3,4

0,9

1,0
16

13,5

2,7

0,7

0,9

69

79,0

$-1,1$

$-1,9$
$-9,9$
10

8,7

23

20,1

$\begin{array}{ll}1,3 & 2,5 \\ 0,4 & 0,6\end{array}$

0,5
137

137

0

-
Trabajadores no cualificados

Absolutos . .

Frecuencia esperada ...

$\begin{array}{lllll}\text { Residuos } & \ldots & \ldots & \ldots & \ldots\end{array}$

Residuos estandarizados

Residuos ajustados ....
50

54,7

$-4,3$

$-0,6$

$-1,0$

$$
\begin{array}{r}
46 \\
48,1 \\
-1,7 \\
-0,3 \\
-0,4
\end{array}
$$

296

281,9

13,7

0,8

2,0

$\begin{array}{rr}30 & 65 \\ 31,0 & 71,7 \\ -0,5 & -7,1 \\ -0,1 & -0,8 \\ -0,2 & -1,5\end{array}$

487

487

0

-

$\begin{array}{rrr}21 & 17 & 101 \\ 20,4 & 18,0 & 105,3 \\ 0,9 & -1,0 & -3,8 \\ 0,2 & -0,2 & -0,4 \\ 0,2 & -0,3 & -0,7\end{array}$

$\begin{array}{rrr}11 & 31 & 182 \\ 11,6 & 26,8 & 182 \\ -0,7 & 4,7 & 0 \\ -0,2 & 0,9 & - \\ -0,2 & 1,1 & -\end{array}$

Total

\begin{tabular}{lrrrrrrr} 
Absolutos . . . . . . . . & 90 & 80 & 466 & 51 & 119 & 806 \\
Frecuencia esperada . . & 90 & 80 & 466 & 51 & 119 & 806 \\
Residuos ... . . . . . & 0 & 0 & 0 & 0 & 0 & 0 \\
Residuos estandarizados & - & - & - & - & - & - \\
Residuos ajustados . . .. & - & - & - & - & - & - \\
\hline
\end{tabular}

$x^{2}=5,91342$

Grados de libertad $=8$

Significación $=0,6569$ 


\section{DIAGRAMA 2C}

Raíces sociales de los partidos en la División Industrial del Trabajo

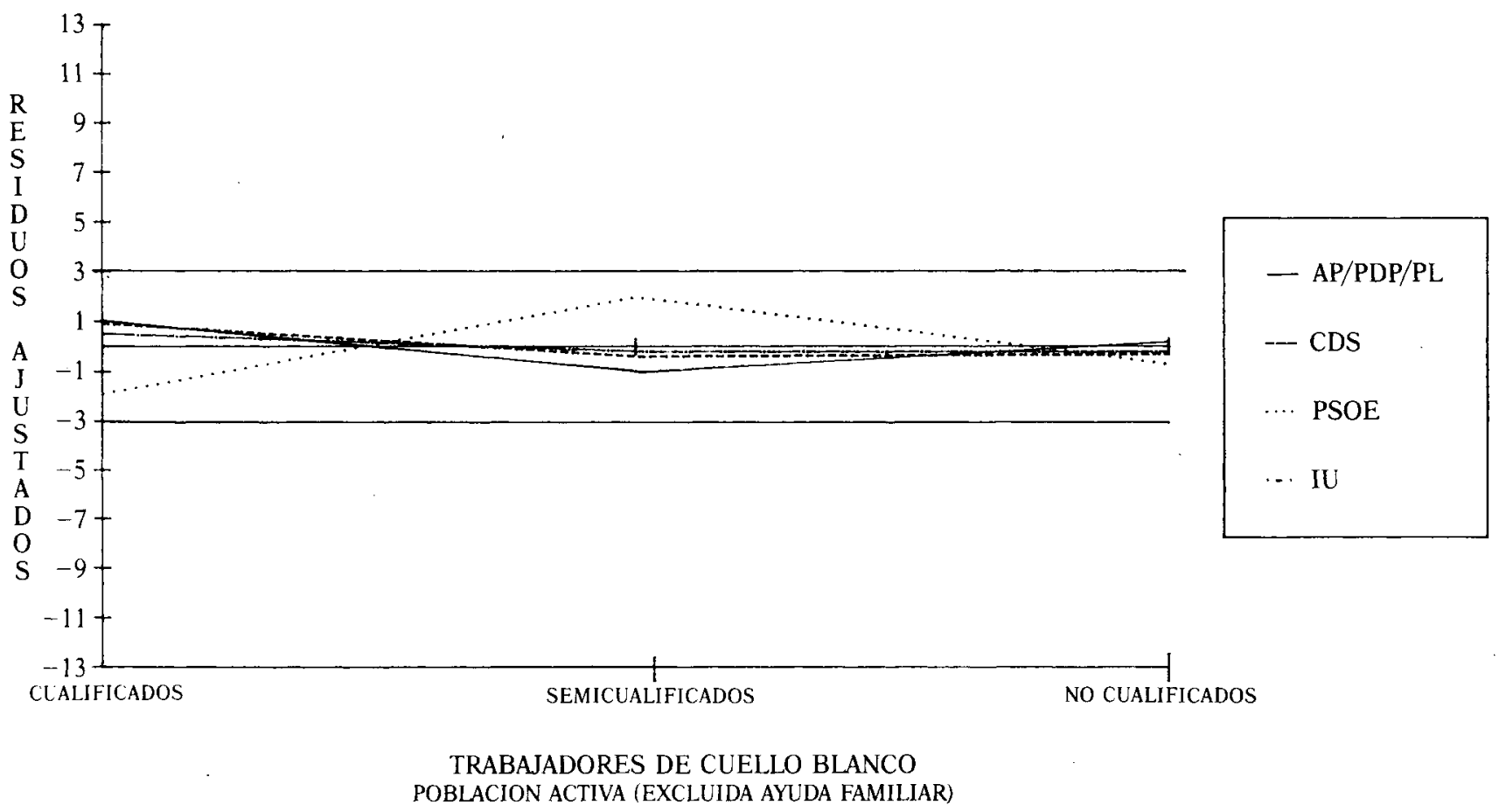


Raíces sociales de los partidos en la División Industrial del Trabajo

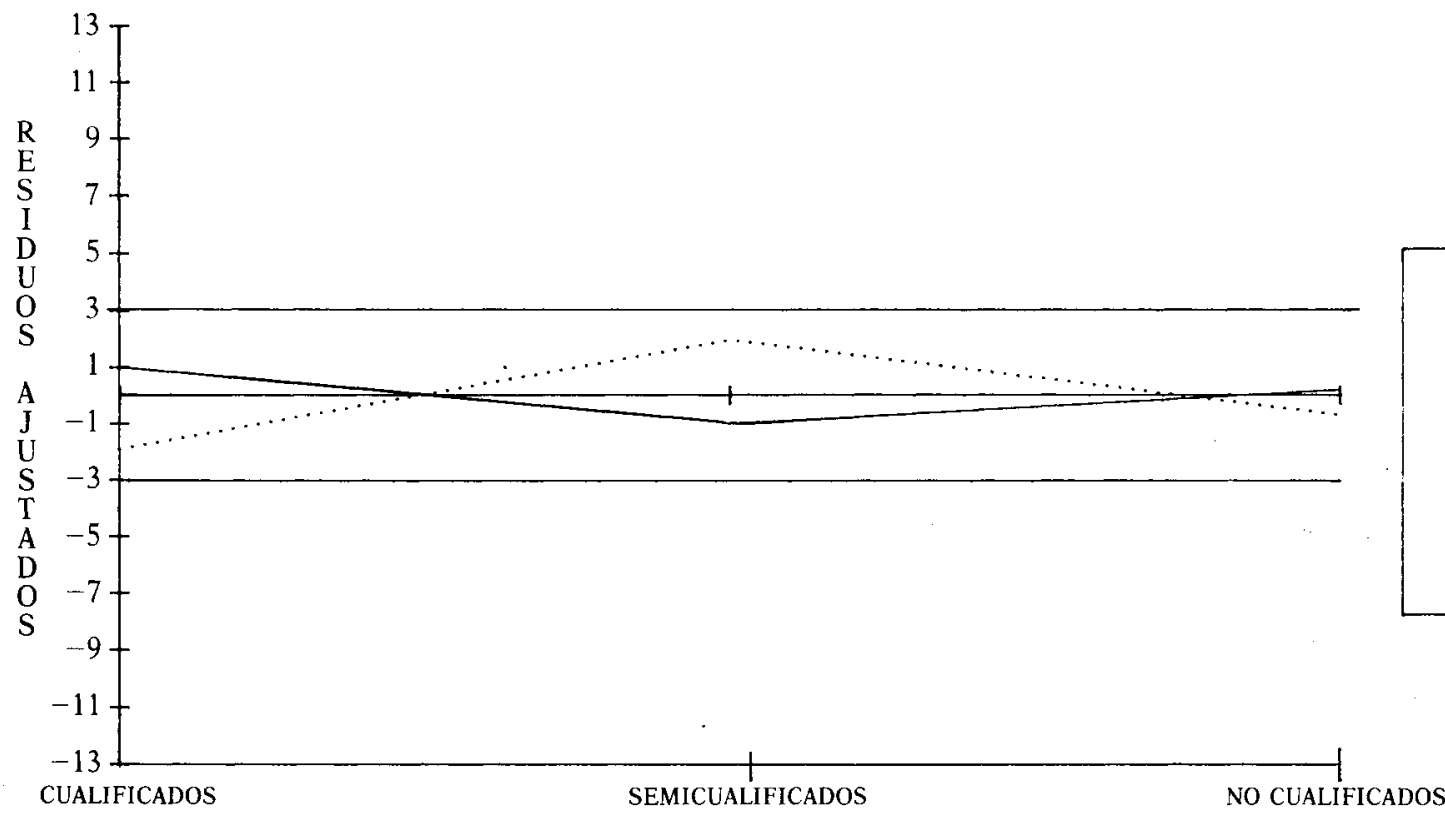

$-\mathrm{AP} / \mathrm{PDP} / \mathrm{PL}$

PSOE

TRABAJADORES DE CUELLO BLANCO

POBLACION ACTIVA (EXCLUIDA AYUDA FAMILIAR) 
TABLA IIIJ

RECUERDO VOTO GENERALES DEL 86

Tipologia por actividad

Trabajadores de cuello azul

Trabajadores cualificados, semicualificados, no

cualificados, supervisores, capataces y trabajadores cualificados

\begin{tabular}{|c|c|c|c|c|c|c|}
\hline Absolutos & 102 & 100 & 731 & 90 & 159 & 1.182 \\
\hline $\begin{array}{ccccc}\% & \text { columna } & \ldots & \ldots & \ldots\end{array}$ & 35,3 & 34,0 & 35,2 & 31,6 & 32,0 & 34,4 \\
\hline$\%$ fila $\ldots \ldots \ldots c c$ & 8,6 & 8,5 & 61,8 & 7,6 & 13,5 & 100,0 \\
\hline$\%$ tabla $\ldots$. & 3,0 & 2,9 & 21,3 & 2,6 & 4,6 & 34,4 \\
\hline
\end{tabular}

Trabajadores semicualificados

Absolutos ... $\ldots \ldots \ldots$....

$\begin{array}{lllll}\% \text { columna } & \ldots & \ldots & \ldots\end{array}$

$\%$ fila $\ldots \ldots \ldots \ldots$

111

629

8,2

37,6

30,3

Absten-

$\%$ tabla $\ldots \ldots \ldots c c$

2,5

10,6

60,0

18,3

$\begin{array}{rr}96 & 125 \\ 34,0 & 25,1 \\ 9,2 & 12,0 \\ 2,8 & 3,6\end{array}$

1.048

30,5

100,0

Trabajadores no cualificados

$\begin{array}{lllll}\text { Absolutos } & \ldots & \ldots & \ldots & \ldots\end{array}$

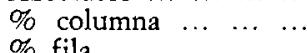

100

84

714

34,4

34,9
8,3

28,5

59,0

$\begin{array}{llllll}\% & \text { tabla } & \ldots & \ldots & \ldots & \ldots\end{array}$

2,9

7,0

20,8

98
34,4
8,1
2,8

214

1.210

30,5

\section{Total}

\begin{tabular}{|c|c|c|c|c|c|c|}
\hline Absolutos ... & 288 & 296 & 2.074 & 284 & 498 & 3.439 \\
\hline$\%$ columna $\ldots \ldots \ldots$ & 100,0 & 100,0 & 100,0 & 100,0 & 100,0 & 100,0 \\
\hline$\%$ fila $\ldots \ldots \ldots c c c c$ & 8,4 & 8,6 & 60,3 & 8,2 & 14,5 & 100,0 \\
\hline$\%$ tabla $\ldots \ldots \ldots c c$. & 8,4 & 8,6 & 60,3 & 8,2 & 14,5 & 100,0 \\
\hline
\end{tabular}




\section{TABLA IIIK}

\section{RECUERDO VOTO GENERALES DEL 86}

$\begin{gathered}A P \cdot P D P \\ P L\end{gathered}$

Tipologia por actividad

Trabajadores de cuello azul

Trabajadores cualificados, semicualificados, no cualificados, supervisores, capataces y trabajadores cualificados

Absolutos ... .........

Frecuencia esperada ...

Residutos $\ldots \ldots \ldots \ldots$

Residuos estandarizados

Residuos ajustados ....

$\begin{array}{rrrrrr}102 & 100 & 731 & 90 & 159 & 1.182 \\ 98,9 & 101,7 & 712,5 & 97,5 & 171,2 & 1.182 \\ 2,7 & -1,2 & 18,3 & -7,9 & -11,9 & 0 \\ 0,3 & -0,1 & 0,7 & -0,8 & -0,9 & - \\ 0,3 & -0,2 & 1,3 & -1,0 & -1,2 & -\end{array}$

Trabajadores semicualificados

Absolutos ... .........

Frecuencia esperada ...

$\begin{array}{llll}\text { Residuos } \ldots \ldots & \ldots & \ldots & \ldots \\ \text { Residuos estandarizados }\end{array}$

Residuos ajustados ...

$\begin{array}{rrrrrr}86 & 111 & 629 & 96 & 125 & 1.048 \\ 87,6 & 90,1 & 631,6 & 86,4 & 151,7 & 1.048 \\ -1,8 & 21,0 & -2,8 & 10,0 & -26,5 & 0 \\ -0,2 & 2,2 & -0,1 & 1,1 & -2,1 & - \\ -0,2 & 2,8 & -0,2 & 1,4 & -2,8 & -\end{array}$

Trabajadores no cualificados

Absolutos ... ... .......

Frecuencia esperada ...

$\begin{array}{llll}\text { Residuos } \ldots & \ldots . & \ldots & \ldots \\ \text { Residuos } & \text {... }\end{array}$

Residuos estandarizados
Residuos ajustados

100

101,2

$-0,9$

$-0,1$

$-0,1$

84
104,1
$-19,8$
$-1,9$
$-2,5$

714
729,4
$-15,5$
$-0,6$
$-1,1$

98

99,8

$-2,2$

$-0,2$

$-0,3$
214

175,2

38,4

2,9

3,9
1.210

1.210

0

Total

Absoiutos . . . . . . . . .

Frecuencia esperada ...

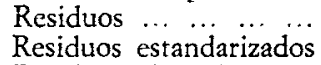

Residuos ajustados ....

$x^{2}=25,32277$

Grados de libertad $=8$

Significación $=0,0014$ 
Raíces sociales de los partidos en la División Industrial del Trabajo

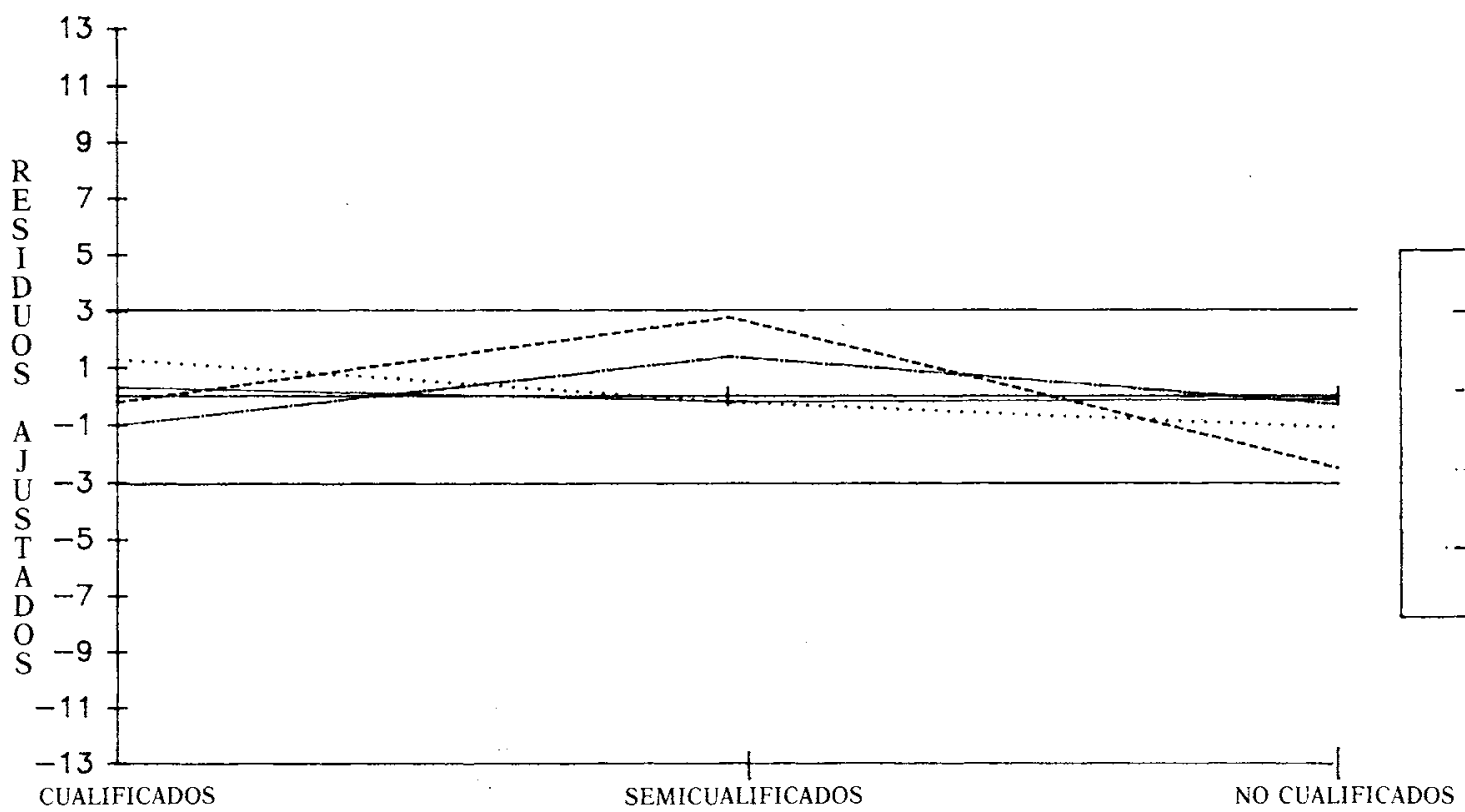

TRABAJADORES DE CUELLO AZUL POBLACION ACTIVA (EXCLUIDA AYUDA FAMILIAR) 


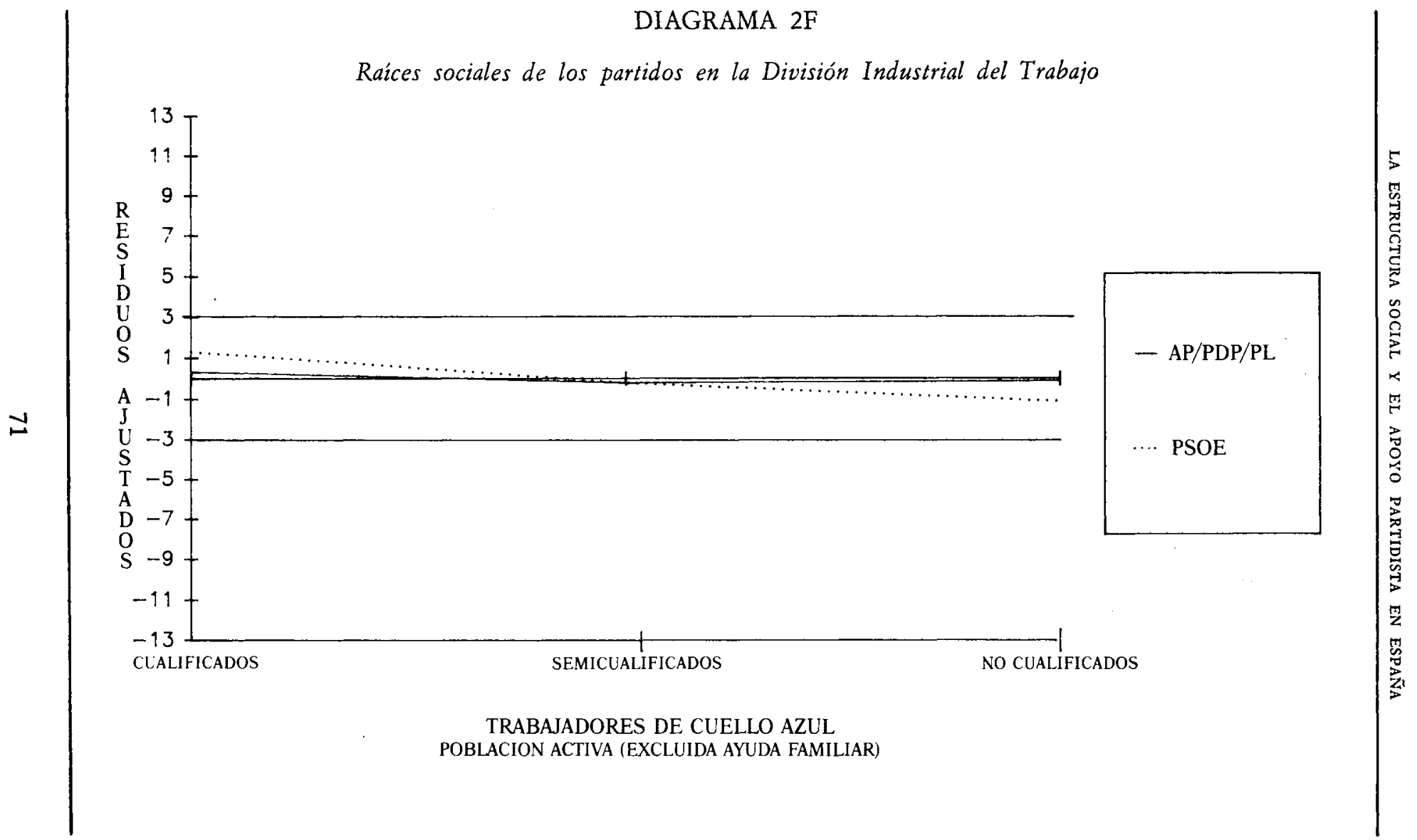




\section{BIBLIOGRAFIA}

Castilloo, Pilar del, y SANi, G. (1986): «Las elecciones de 1986: continuidad sin consolidación», en J. Linz y J. R. Montero.

Everitt, B. S. (1977): The analysis of Contingency tables, Londres: Chapman and Hall; Nueva York: A Halsted Press Book, John Wiley \& Sons Inc.

Gramsci, A. (1984): Notas sobre Maquiavelo, sobre la politica y sobre el Estado moderno, Buenos Aires: Nueva Visión.

Gunther, R. (1985): «Un análisis preliminar de las alteraciones producidas en 1982 en el sistema español de partidos», Sistema, núm. 68.

Gunther, R.; Sani, G., y Shabad (1986): Spain after Franco: The making of a competitive Party System, University of California Press.

Haberman, S. J. (1973): "The analysis of residuals in cross-classified tables», Biometrics, $29,205-220$.

Linz, J. (1986): «Consideraciones finales», en J. Linz y J. R. Montero (eds.), Crisis y Cambio: electores y partidos de los ochenta, Madrid: Centro de Estudios Constitucionales.

Lipset, S. M. (1981): Political man, Baltimore: The Johns Hopkins University Press.

Maravall, J. M." (1979): «Political Cleavages in Spain and the 1979 General Election», Government and Opposition, vol. 14, núm. 3.

- (1981): «Los apoyos partidistas en España: polarización, fragmentación y estabilidad», Revista de Estudios Políticos, núm. 23 (Nueva Epoca).

Maravall, J. M. ${ }^{2}$, y Santamarí, J. (1985): «Crisis del franquismo, transición política y consolidación de la democracia en España», Sistema, núm. 68.

Norussis, M. J. (1985): SPSSPC +, Chicago, Ill.: SPSS Inc.

Sánchez Carrión, J. J. (1989): Análisis de tablas de contingencia, Madrid: Centro de Investigaciones Sociológicas, Colección «Monografías», núm. 105.

Sani, G.; Gunther, R., y Shabad (1979): «Estrategias de los partidos y escisiones de masas en las elecciones parlamentarias españolas de 1979», Revista de Derecho Político, núm. 11.

Sani, G., y Shabad (1986): «¿Adversarios o competidores?», en J. Linz y J. R. Montero.

SAS Institute Inc. (1985): SAS Language Guide for Personal Computers, Version 6 edition, Cary, NC: SAS Institute Inc.

- (1985): SAS Procedures Guide for Personal Computers, Version 6 edition, Cary, NC: SAS Institute Inc.

- (1987 ed.): SAS Guide to Tabulate Processing, Cary, NC: SAS Institute Inc.

SArtori, G. (1980): Partidos y sistemas de partidos, Madrid: Alianza Editorial.

WeBER, M. (1964): The Theory of Social and Economic Organization, Nueva York: The Free Press. 